\title{
Early Activation of Sphingosine Kinase in Mast Cells and Recruitment to FceRI Are Mediated by Its Interaction with Lyn Kinase
}

\author{
Nicole Urtz, ${ }^{1}$ Ana Olivera, ${ }^{2}$ Elisa Bofill-Cardona, ${ }^{1}$ Robert Csonga, ${ }^{1}$ Andreas Billich, ${ }^{1}$ \\ Diana Mechtcheriakova, ${ }^{1}$ Frederic Bornancin, ${ }^{1}$ Max Woisetschläger, ${ }^{1}$ \\ Juan Rivera, ${ }^{2}$ and Thomas Baumruker ${ }^{1 *}$ \\ Novartis Institute for Biomedical Research Vienna, Vienna, Austria, ${ }^{1}$ and Molecular Immunology \\ and Inflammation Branch, National Institutes of Health, Bethesda, Maryland ${ }^{2}$
}

Received 28 January 2004/Returned for modification 1 April 2004/Accepted 6 July 2004

\begin{abstract}
Sphingosine kinase has been recognized as an essential signaling molecule that mediates the intracellular conversion of sphingosine to sphingosine-1-phosphate. In mast cells, induction of sphingosine kinase and generation of sphingosine-1-phosphate have been linked to the initial rise in $\mathrm{Ca}^{2+}$, released from internal stores, and to degranulation. These events either precede or are concomitant with the activation of phospholipase $C-\gamma$ and the generation of inositol trisphosphate. Here we show that sphingosine kinase type 1 (SPHK1) interacts directly with the tyrosine kinase Lyn and that this interaction leads to the recruitment of this lipid kinase to the high-affinity receptor for immunoglobulin E (FceRI). The interaction of SPHK1 with Lyn caused enhanced lipid and tyrosine kinase activity. After FceRI triggering, enhanced sphingosine kinase activity was associated with FceRI in sphingolipid-enriched rafts of mast cells. Bone marrow-derived mast cells from $\mathrm{Lyn}^{-1-}$ mice, compared to syngeneic wild-type cells, were defective in the initial induction of SPHK1 activity, and the defect was overcome by retroviral Lyn expression. These findings position the activation of SPHK1 as an FceRI proximal event.
\end{abstract}

In addition to the importance of sphingolipids in membrane structure, the sphingomyelin pathway with its lipid products ceramide, sphingosine (S), and S-1-phosphate (S1P) has been recognized to function in a variety of signaling events $(3,36)$. Many of the sphingolipids generated along this pathway are secreted and bind specific cellular receptors on a variety of cell types. On the other hand, they also function intracellularly as "second messenger molecules" similar to the various intermediates of phosphoglyceride metabolism $(3,36)$. Processes such as apoptosis, differentiation, and cell activation are directly regulated or fine-tuned by ceramide and its derivatives. However, in contrast to glycerolipids, the individual concentrations of various intracellular sphingolipids serve to balance cell activation and inactivation. This concept has been termed the sphingolipid rheostat (3). Specific examples include ceramide and $\mathrm{S} 1 \mathrm{P}$, whose relative intracellular concentration regulates apoptosis; S and S1P, which regulates immunoglobulin E-antigen (IgE-Ag) sensitivity in mast cells; and ceramide and ceramide-1-phosphate, which regulates the process of phagocytosis in macrophages $(2,14,29,37,42,43)$. An essential cellular checkpoint in the sphingomyelin signaling pathway is $\mathrm{S}$ kinase (SPHK), as its product S1P is able to counteract ceramide as well as S-mediated effects in apoptosis and effector function regulation (e.g., inhibition of cytokine induction by $\mathrm{S}$ in mast cells). In humans, two different isoforms and several splice variants of SPHK were described and cloned (34). While acti-

\footnotetext{
* Corresponding author. Mailing address: Novartis Institute for Biomedical Research, Brunner Strasse 59, A-1235 Vienna, Austria. Phone: 43186634 527. Fax: 43186634 582. E-mail: thomas.baumruker @ pharma.novartis.com.
}

vation of SPHK1 has been firmly established (e.g., after FceRI and Fc $\gamma$ RI signaling), its relationship to other known mast cell signaling molecules is still unexplored $(24,37)$. Recent data on Fc $\gamma$ RI positioned SPHK downstream of phospholipase D, with a dependence on phosphatidic acid, similar to the demonstrated requirements for activation by FceRI $(24,25)$. However, SPHK activity is stimulated by many other triggers, including platelet-derived growth factor, tumor necrosis factor alpha, nerve growth factor, muscarinic acetylcholine agonists, and serum and phorbol esters, though the mechanisms leading to cell type-specific SPHK activation are not fully understood (9, 21, 26, 31, 47, 48). Recently, protein kinase C (PKC)dependent membrane translocation of SPHK by phorbol ester stimulation of HEK293 cells was described, providing another possible clue in SPHK activation (46). In addition, by using the yeast two-hybrid system, several interacting proteins have been isolated. These include tumor necrosis factor alpha receptorassociated factor 2, protein kinase A anchoring protein-related protein, and RPK118, but the function of these molecules (as adaptors) and their effects on SPHK activity still remains unclear $(13,19,49)$.

Herein we demonstrate that, in mast cells, SPHK directly interacts with the $s r c$ family tyrosine kinase Lyn, providing a possible mechanistic explanation of the previous finding that the activity of this lipid kinase is increased after FceRI triggering (37). We now provide evidence that Lyn recruits SPHK to FceRI during IgE-dependent mast cell activation and that a complex of SPHK and Lyn features enhanced lipid and tyrosine kinase activity. The importance of Lyn for SPHK activation is further demonstrated by the loss of the initial rise of SPHK activity in FceRI-triggered mast cells generated from 
$\mathrm{Lyn}^{-1-}$ mice and by the restoration of this defect when Lyn is reintroduced in these cells.

\section{MATERIALS AND METHODS}

Western blot analysis, SPHK assays and lipid extractions, sodium dodecyl sulfate-polyacrylamide gel electrophoresis (SDS-PAGE), raft isolations via sucrose gradients, culture, and differentiation conditions as well as stimulations by IgE-Ag for bone marrow-derived mast cells (BMMC) (and CPII mouse mast cells) and electroporation of CPII cells were as recently described (37-39).

Reagents, antibodies, and kits. A TNT T7 Quick coupled transcription and translation system was obtained from Promega. A signal transduction antibody (Ab) array was purchased from Hypromatrix. Rabbit antibodies or antisera for immunoprecipitation (IP) of linker of activated T cells (LAT), Lyn, Syk, and p53 were from Santa Cruz, the monoclonal Ab to $m y c$ was from Clontech (isotype IgG1), the antiserum to FceRI $\gamma$ was from Upstate, and the monoclonal Ab to Flag M2 was from Sigma-Aldrich (isotype IgG1). Rabbit antibodies or antisera for Western blot detection of LAT, PI3K (directed against $\mathrm{p} 85$ subunit), myc, and FceRI $\gamma$ were from Upstate, Ab to p42/44 Erk was from Cell Signaling, while the monoclonal $\mathrm{Ab}$ to Lyn (isotype $\operatorname{IgG} 2 \alpha$ ) and the rabbit polyclonal antiserum to Syk and to p53 were from Santa Cruz. Protein G Sepharose 4 Fast Flow was obtained from Amersham Pharmacia Biotech. $\left[{ }^{35} \mathrm{~S}\right]$ methionine and $\left[\gamma_{-}{ }^{32} \mathrm{P}\right] \mathrm{ATP}$ were also purchased from Amersham Pharmacia Biotech, and D-erythro $\left[3-{ }^{3} \mathrm{H}\right] \mathrm{S}$ was from ARC. S, 1- $\beta$-D-galactosylsphingosine, 1- $\beta$-D-glucosylsphingosine, and doxycycline were obtained from Sigma-Aldrich. The tyrosine kinase (Src family) substrate peptide pack, including [Lys19] cdc2 peptide and human recombinant c-Jun protein, was from Upstate. Human recombinant Lyn protein (hLyn) was from Calbiochem, and human recombinant and highly enriched Syk preparations were from Novartis.

Cell culture and stimulation. HeLa clone 12 cells, harboring the human FceRI (1; M. Woisetschläger, unpublished data), were cultured in Dulbecco's modified Eagle medium (Gibco, Invitrogen) containing 10\% fetal bovine serum (Tet system approved; Clontech), $10 \mathrm{mM}$ HEPES (pH 7.3), penicillin (100 IU/ml)streptomycin $(100 \mu \mathrm{g} / \mathrm{ml}), 2 \mathrm{mM}$ L-glutamine, geneticin $(500 \mu \mathrm{g} / \mathrm{ml})$, and hygromycin $\left(600 \mu \mathrm{g} / \mathrm{ml}\right.$; Gibco, Invitrogen). BMMC from wild-type and $\mathrm{Lyn}^{-/-}$mice [strain C57BL6J-Lyn(N6); Jackson Laboratory] were cultured as described previously (40) in media supplemented with $20 \mathrm{ng}$ of interleukin-3 (IL-3)/ml and 20 ng of stem cell factor (SCF)/ml. Differentiation of mast cells was monitored as previously described (40). Cells were used when greater than $95 \%$ of the population expressed FceRI. Cells were sensitized with $2 \mu \mathrm{g}$ of murine $\mathrm{IgE} / \mathrm{ml}$ and stimulated with $100 \mathrm{ng}$ of 2,4-dinitrophenol (DNP)-bovine serum albumin (BSA) (Calbiochem) $/ \mathrm{ml}$.

Cloning. The murine Lyn (mLyn) coding region was cloned into the pDual GC expression vector (Stratagene) using PCR amplification. The primers $5^{\prime}$ cgctctt cgATGGGATGTATTAAATCAAAAAGGAA $3^{\prime}$ and $5^{\prime}$ cgctcttcgaagCTACGG TTGCTGCTGATACTG 3', containing Eam1104I restriction enzyme sites (given in lowercase letters), were used for amplification. The conditions for PCR amplification were as follows: 35 cycles of $94^{\circ} \mathrm{C}$ for $30 \mathrm{~s}, 60^{\circ} \mathrm{C}$ for $45 \mathrm{~s}$, followed by $68^{\circ} \mathrm{C}$ for $2.5 \mathrm{~min}$. mSPHK 1 and mp53 were cloned analogously by using the primers $5^{\prime}$ ggctcttCTATGGAACCAGAATGCCCTCG $3^{\prime}$ and 5' ggctcttcgaagT GGTTCTTCTGGAGGTGGCC $3^{\prime}$ for SPHK1 and 5' cgctcttcgATGACTGCC ATGGAGGAGT $3^{\prime}$ and $5^{\prime}$ cgctcttcgaagCTATCAGTCTGAGTCAGGCCC $3{ }^{\prime}$ for mp53, each containing Eam1104I restriction enzyme sites for cloning (given in lowercase letters)

Ab array and hybridization. The mSPHK1 was expressed in a coupled in vitro transcription and translation system from a pDual GC vector background (as a myc tag version) using the TNT T7 reticulocyte lysate system in the presence of $\left.{ }^{35} \mathrm{~S}\right]$ methionine, as described by the supplier. Mast cell lysates were generated from a total of $10^{7} \mathrm{BMMC}$, stimulated for 5 or $10 \mathrm{~min}$ by IgE-Ag before lysing them in a buffer (lysis buffer: $15 \mathrm{mM}$ Tris [pH 7.5], $120 \mathrm{mM} \mathrm{NaCl}, 25 \mathrm{mM} \mathrm{KCl}$, $2 \mathrm{mM}$ EDTA, $2 \mathrm{mM}$ EGTA, $0.1 \mathrm{mM}$ dithiothreitol [DTT], 0.5\% Triton X-100, $10 \mu \mathrm{g}$ of leupeptin/ml, and $0.5 \mathrm{mM}$ phenylmethylsulfonyl fluoride [PMSF]) at $4^{\circ} \mathrm{C}$ for $20 \mathrm{~min}$. Insoluble material was removed by centrifugation for $15 \mathrm{~min}$ at $4^{\circ} \mathrm{C}$ and 13,000 rpm in a Heraeus Biofuge microcentrifuge. The protein concentration was measured using the bicinchoninic assay kit (Pierce) and adjusted to 5 $\mathrm{mg} / \mathrm{ml}$. Two milliliters of lysates ( $1 \mathrm{ml}$ of 5- and 10-min-stimulated BMMC each) was incubated with $250 \mu \mathrm{l}$ of $\left[{ }^{35} \mathrm{~S}\right]$ methionine-labeled mSPHK1 from the transcription and translation reaction and brought to a 5-ml volume with lysis buffer (containing 1\% dry milk), and the formation of protein complexes was for $1 \mathrm{~h}$ at room temperature under gentle shaking. This mixture was then further incubated with the $\mathrm{Ab}$ array membrane for $90 \mathrm{~min}$ to allow binding of protein/SPHK complexes by the corresponding $\mathrm{Ab}$. The membrane was then washed three times for 15 min each with TBST buffer ( $150 \mathrm{mM} \mathrm{NaCl}, 25 \mathrm{mM}$ Tris [pH 7.5], $0.05 \%$ Tween 20) and subjected to autoradiography using an intensifier screen.

IPs in vitro. Proteins generated by in vitro transcription and translation were allowed to form complexes in lysis buffer-low Triton (15 mM Tris [pH 7.5], 120 $\mathrm{mM} \mathrm{NaCl}, 25 \mathrm{mM} \mathrm{KCl}, 2 \mathrm{mM}$ EDTA, 2 mM EGTA, $0.1 \mathrm{mM}$ DTT, $0.1 \%$ Triton $\mathrm{X}-100,10 \mu \mathrm{g}$ of leupeptin/ml, $0.5 \mathrm{mM}$ PMSF) for $1 \mathrm{~h}$ at room temperature. Samples were added to tubes containing $\mathrm{Ab}$ or antisera to myc, Lyn, and p53, prebound to protein G Sepharose, and further incubated for $2 \mathrm{~h}$ at $4^{\circ} \mathrm{C}$. Immunoprecipitates were collected by centrifugation, washed three times with Trisbuffered saline (150 mM NaCl, $25 \mathrm{mM}$ Tris [pH 7.5]), resuspended in SDS loading buffer, and separated by SDS-PAGE (4 to $20 \%$ Tris-glycine gels; Invitrogen). Gels were subsequently fixed in $40 \%$ methanol- $10 \%$ acetic acid, dried, and subjected to autoradiography.

IPs from cells. Twenty-four hours prior to transfection, HeLa cells $\left(4 \times 10^{5}\right.$ each) were seeded in 60-mm culture dishes in full growth medium; $12 \mathrm{~h}$ prior to transfection doxycycline $(2 \mu \mathrm{g} / \mathrm{ml})$ was added to induce FceRI expression. Effectene transfection reagent (QIAGEN) was used for transient transfection according to the manufacturer's protocol in the presence of full growth medium and doxycycline. Forty-eight hours after transfection, cells were harvested and washed with ice-cold phosphate-buffered saline (PBS) and lysed as described above under conditions that maintain the integrity of FceRI. For co-IP of SPHK from the extracts of HeLa cells, antibodies to FceRI $\gamma$, Flag epitope, Lyn, myc, and p53 were prebound to protein G Sepharose and incubated with the cell lysates for $2 \mathrm{~h}$ at $4^{\circ} \mathrm{C}$. After precipitation by centrifugation and three washing steps, half of the beads were resuspended in $70 \mu \mathrm{l}$ of SPHK buffer $(50 \mathrm{mM}$ HEPES, $50 \mathrm{mM} \mathrm{LiCl}, 15 \mathrm{mM} \mathrm{MgCl} 2,15 \mathrm{mM} \mathrm{CaCl} 2,1 \mathrm{mM}$ EDTA, $1 \mathrm{mM}$ EGTA). Subsequently ATP (final concentration, $10 \mu \mathrm{M}$ ), S (final concentration, $10 \mu \mathrm{M})$, and $\left[\gamma^{32} \mathrm{P}\right] \mathrm{ATP}(5 \mu \mathrm{Ci})$ were added and incubated for $45 \mathrm{~min}$ at $30^{\circ} \mathrm{C}$. Lipids were extracted and analyzed by thin-layer chromatography (TLC) (nbutanol-acetic acid- $\left.\mathrm{H}_{2} \mathrm{O}, 6: 2: 2\right)$. After drying, the plate was subjected to autoradiography. The detected S1P levels were normalized to total extracted S, which was determined by Fluram staining (detects the primary amine of S) (5). Additionally, where possible, the remaining half of the beads were used in Western blot analysis to calibrate for the amount of recovered protein G Sepharose beads and/or the specific protein precipitated. All IPs were performed identically.

Lyn kinase assays. Recombinant hLyn at various concentrations and recombinant hSPHK1 were diluted in lysis buffer-low Triton and incubated for $1 \mathrm{~h}$ at room temperature, allowing complex formation. Afterwards, $10 \mu$ lof the peptide substrate $\left\{\left[\right.\right.$ Lys19] cdc2 (6-20)- $\left.\mathrm{NH}_{2}\right\}, 10 \mu \mathrm{l}$ of Src reaction buffer (100 mM Tris [pH 7.2], $125 \mathrm{mM} \mathrm{MgCl}_{2}, 25 \mathrm{mM} \mathrm{MnCl}, 2 \mathrm{mM}$ EGTA, $0.25 \mathrm{mM}$ sodium orthovanadate, $2 \mathrm{mM}$ DTT), and $10 \mu \mathrm{l}$ of ATP cocktail ( $75 \mathrm{mM} \mathrm{MnCl}_{2}, 5 \mu \mathrm{M}$ rATP in $20 \mathrm{mM}$ morpholinepropanesulfonic acid [pH 7.2], $25 \mathrm{mM} \beta$-glycerol phosphate, $5 \mathrm{mM}$ EGTA, $1 \mathrm{mM}$ sodium orthovanadate, $1 \mathrm{mM}$ DTT) including $5 \mu \mathrm{Ci}$ of $\left[\gamma_{-}{ }^{32} \mathrm{P}\right] \mathrm{ATP}$ were added to hLyn or hLyn/hSPHK1 complexes, and the reaction was incubated at $30^{\circ} \mathrm{C}$ for $10 \mathrm{~min}$ with subsequent SDS-PAGE separation (16\% Tricine gel; Invitrogen). Lyn autophosphorylation and the possible phosphorylation of hSPHK by Lyn kinase were measured (in the absence of peptide substrate) and analyzed on 4 to $20 \%$ Tris-glycine gels (Invitrogen). After electrophoresis, the gels were fixed in $40 \%$ methanol-10\% acetic acid overnight, dried, and subjected to autoradiography. For assays in which FceRI $\gamma$ was used as a substrate, lysates of $4 \times 10^{7}$ mast cells were incubated with $\mathrm{Ab}$ to FceRI $\gamma$ prebound to protein G Sepharose. After precipitation and washing, $30 \mu \mathrm{l}$ of the beads was added either to hLyn alone or to hLyn/hSPHK1 complexes. The same Src reaction buffer, ATP cocktail, and assay conditions as described above were used. Proteins were resolved by 4 to $20 \%$ Tris-glycine gels (Invitrogen).

S-binding dot blots. hLyn, hFyn (Upstate), hSPHK1 (see below), hc-Jun (Gst fusion protein; amino acids 1 to 169) (Upstate), hPKC $\alpha$ (Calbiochem), hErk1 (Upstate), and Flag protein (Novartis) were dotted on a polyvinylidene difluoride membrane $(0.2-\mu \mathrm{m}$ pore size; Invitrogen). The membrane was blocked with TBST plus 5\% dry milk (150 mM NaCl, $25 \mathrm{mM}$ Tris [pH 7.5], 0.05\% Tween 20) for $1 \mathrm{~h}$ at room temperature. $\left[{ }^{3} \mathrm{H}\right] \mathrm{S}(15 \mu \mathrm{Ci})$ was diluted in TBST plus $0.5 \%$ dry milk and incubated with the membrane for $1 \mathrm{~h}$. After washing (three times in TBST plus $0.1 \%$ milk), the membrane was dried and subjected to autoradiography.

Cloning and expression of hSPHK1. The 1,155-bp coding sequence for hSPHK1 was amplified by PCR from a human fetal cDNA library (Clontech) using primers GCCACCATGGATCCAGCGGGCGGCCCC and TCATAAGG GCTCTTCTGGCGGTGGCATCTG and cloned into the vector pCR2.1-TOPO (Invitrogen). For recombinant protein expression, hSPHK1 was amplified using primers GCATTAGAATTCATGGATCCAGCGGGCGGCCCC and TAACG CGTCGACTCATAAGGGCTCTTCTGGCGGTGGCATCTG; the product was digested with EcoRI and SalI and ligated with EcoRI/SalI-digested pET32a $(+)$ vector (Novagen); thus, the hSPHK1 coding sequence was fused in frame with 
N-terminal Escherichia coli thioredoxin (Trx). The E. coli strain BL21(DE3) (Novagen) was transfected with the expression plasmid. Bacteria were cultured in Luria-Bertani medium with $100 \mu \mathrm{g}$ of ampicillin/ml. For protein production, 5 liters of medium was inoculated with $50 \mathrm{ml}$ of an overnight culture, and bacteria were grown at $37^{\circ} \mathrm{C}$ to optical density at $600 \mathrm{~nm}$ of 0.6 to 0.7 . The temperature was then shifted to $28^{\circ} \mathrm{C}$ and isopropyl- $\beta$-D-thiogalactopyranoside was added to a final concentration of $1 \mathrm{mM}$. Three hours after induction, cells were harvested, washed once with PBS, and frozen at $-80^{\circ} \mathrm{C}$. For protein purification, the cell pellet from a 5-liter culture was thawed and suspended in $250 \mathrm{ml}$ of ice-cold PBS containing 2.5\% Trasylol (Bayer). Cells were lysed using a French press (two passages, $100 \mathrm{lb} / \mathrm{in}^{2}$; Aminco). Triton X-100 was added to a final concentration of $2 \%$, followed by sonication (two times for $1 \mathrm{~min}, 50 \mathrm{~W}$ ). The lysate was centrifuged $(30 \mathrm{~min}, 16,000 \times g)$. The pellet was discarded, and the supernatant was applied onto a Ni-nitrilotriacetic acid column ( 1 by $8 \mathrm{~cm}$; QIAGEN), equilibrated with buffer 1 (PBS, $2.5 \%$ Trasylol, $2 \%$ Triton X-100), and operated at a flow rate of $1.5 \mathrm{ml} / \mathrm{min}$. The column was first washed with buffer 1 and then with buffer 2 (10 mM imidazole-HCl [pH 7.5], 1\% Triton X-100, 10\% glycerol, $10 \mathrm{mM}$ $\mathrm{MgCl}_{2}, 10 \mathrm{mM}$ 2-mercaptoethanol, 2.5\% Trasylol). The fusion protein was eluted with buffer 3 (200 mM imidazole- $\mathrm{HCl}$ [pH 7.5], $250 \mathrm{mM} \mathrm{NaCl}, 0.5 \%$ Triton X-100, $10 \%$ glycerol, $10 \mathrm{mM} \mathrm{MgCl}_{2}, 10 \mathrm{mM}$ 2-mercaptoethanol, $2.5 \%$ Trasylol). Fractions were tested for enzymatic activity. Active fractions were pooled and dialyzed against buffer 4 (25 mM Tris [pH 7.4], $1 \mathrm{mM} \mathrm{1,4-dithio-}$ erythritol, $10 \%$ glycerol, $0.1 \%$ Triton $\mathrm{X}-100,0.1 \mathrm{M} \mathrm{NaCl}, 4 \mathrm{mM} \mathrm{CaCl} 2$ ). The material was applied to a calmodulin Sepharose column (1 by $6 \mathrm{~cm}$; Pharmacia), equilibrated with buffer 4 , and operated at a flow rate of $1 \mathrm{ml} / \mathrm{min}$. The column was washed with 5 volumes of buffer 4 and then eluted with buffer 5 (25 mM Tris [pH 7.4], $1 \mathrm{mM}$ 1,4-dithioerythritol, $10 \%$ glycerol, $0.05 \%$ Triton X-100, $1 \mathrm{M}$ $\mathrm{NaCl}, 2$ mM EGTA). Active fractions were pooled and stored in aliquots at $-80^{\circ} \mathrm{C}$. Resolution of proteins by SDS-PAGE showed the final preparation to contain a single band at approximately $60 \mathrm{kDa}$ (theoretical $M_{\mathrm{r}}, 60,490$ ). From a 5 -liter culture of the recombinant bacteria, $226 \mu \mathrm{g}$ of Trx-SPHK fusion protein was obtained.

SPHK activity measurement and retroviral transduction of Lyn-deficient BMMC. BMMC were washed and incubated in SCF-free media for 20 to $24 \mathrm{~h}$ and then sensitized with $1-\mu \mathrm{g} / \mathrm{ml}$ anti-DNP mouse IgE in IL-3-free media containing $2 \%$ fetal bovine serum for three additional hours. Cells were washed twice and resuspended in Tyrode-BSA buffer $\left(37^{\circ} \mathrm{C} ; 20 \mathrm{mM}\right.$ HEPES buffer $[\mathrm{pH}$ 7.4], $135 \mathrm{mM} \mathrm{NaCl}, 5 \mathrm{mM} \mathrm{KCl}, 1.8 \mathrm{mM} \mathrm{CaCl}_{2}, 1 \mathrm{mM} \mathrm{MgCl}_{2}, 5.6 \mathrm{mM}$ glucose, $0.05 \% \mathrm{BSA}$ ) at a density of $3 \times 10^{7}$ cells $/ \mathrm{ml}$, aliquoted, and activated with equal volumes of $200-\mathrm{ng} / \mathrm{ml} \mathrm{DNP}$ for the indicated time. The reaction was stopped by addition of $3 \mathrm{ml}$ of cold PBS containing $100 \mu \mathrm{M}$ sodium orthovanadate. Cells were pelleted and resuspended in buffer A (50 mM Tris [pH 7.4], $100 \mathrm{mM} \mathrm{KCl}$, $10 \%$ glycerol, $1 \mathrm{mM}$ mercaptoethanol, $1 \mathrm{mM}$ EDTA, $1 \mathrm{mM}$ sodium orthovanadate, $40 \mathrm{mM} \beta$-glycerophosphate, $15 \mathrm{mM} \mathrm{NaF}, 5 \mathrm{mM}$ sodium pyrophosphate, 10 $\mu \mathrm{g}$ [each] of leupeptin, aprotinin, and pepstatin/ml, $1 \mathrm{mM}$ PMSF, $0.5 \mathrm{mM}$ 4-deoxypyridoxine) and lysed by freeze-thawing. Cell lysates were centrifuged at $21,000 \times g$ for $30 \mathrm{~min}$. Thus, the lysates likely contained some small membrane fragments. Twenty micrograms of the lysate was used to measure SPHK activity. SPHK activity was measured essentially as described previously (30) by incubating cell samples with $50 \mu \mathrm{M} \mathrm{S}$ and $\left[\gamma-{ }^{32} \mathrm{P}\right] \mathrm{ATP}(0.5 \mu \mathrm{Ci}, 1 \mathrm{mM})$ containing $\mathrm{MgCl}_{2}$ $(10 \mathrm{mM})$ in a final volume of $200 \mu \mathrm{l}$ of buffer for $20 \mathrm{~min}$ at $37^{\circ} \mathrm{C}$. Labeled lipids were extracted and resolved by TLC as described previously (30), and $\left.{ }^{32} \mathrm{P}\right] \mathrm{S} 1 \mathrm{P}$ was quantified with a Molecular Dynamics Storm phosphorimager. SPHK specific activity was expressed as picomoles of S1P formed per min per mg of protein. To preferentially measure SPHK1 activity, cell extracts were assayed in duplicate samples, taking advantage of the differential biochemical properties of the two isoforms of SPHKs (20). Detailed measurements in either SPHK1 or SPHK2 highly overexpressing HEK cells confirmed that under these specific conditions the activity of each SPHK can be measured separately with no more than $20 \%$ cross-contamination (data not shown). S for the SPHK1 assay was prepared in mixed micelles with Triton X-100 (final concentration, 0.25\%) (20).

Retroviral transduction of BMMC to reconstitute the expression of Lyn in gene-deleted mice was as previously described (41). The retroviral wild-type Lyn construct used in these studies was kindly provided by Kenneth W. Harder and Margaret L. Hibbs (Ludwig Institute for Cancer Research, Melbourne, Australia). Briefly, 10-day-old bone marrow cultures were infected with retrovirus carrying the gene for wild-type Lyn, internal ribosomal entry site-green fluorescent protein, and antibiotic resistance to puromycin as a selection marker. After transduction, cells were rested for $48 \mathrm{~h}$ and then selected in IL-3- and SCFsupplemented media containing $0.8 \mathrm{mg}$ of puromycin $/ \mathrm{ml}$. After 2 weeks of selection, cells were assayed for green fluorescent protein expression and for expression of Lyn kinase. Expression of Lyn remained stable for up to 8 weeks, and cultures were $>98 \%$ FceRI positive by 28 days. Lyn expression was verified by Western blot analysis.

\section{RESULTS}

Recently, we described a SPHK-dependent rheostat mechanism comprised of the two sphingolipids S and S1P (SPHK substrate and product) that regulates the initial molecular signaling events after engagement of the FceRI on mast cells (37). To position SPHK hierarchically in the initial signaling events, we focused on identifying mast cell proteins that interact directly or indirectly with this kinase. Experimentally, an Ab array approach was used to search for associated proteins. In vitro transcribed and translated, radiolabeled murine SPHK (mSPHK1; as a C-terminally myc-tagged version) was incubated with whole-cell lysates, generated from IgE-Ag-stimulated BMMC, and allowed to form possible complexes with proteins in these lysates. This mixture was then incubated with an $\mathrm{Ab}$ array harboring about 500 defined monoclonal Abs to a variety of signaling molecules. This array included an $\mathrm{Ab}$ directed to the myc tag of the in vitro transcribed and translated mSPHK1, which served as a positive control recognizing the radiolabeled enzyme directly (Fig. 1A). Four additional spots were also detected in this experiment (Fig. 1A). These additional spots had diminished intensity (fivefold less) in signal strength compared to the positive control, which may be attributed to indirect ( $\mathrm{Ab} /$ protein/protein) versus direct $(\mathrm{Ab} /$ protein) interaction. Nonetheless, other factors such as the concentration of the respective proteins in the mast cell extracts and the affinity of the interactions may influence the signal intensity. The four potential interacting partners were identified as Sam68, Bin-1, clathrin, and Lyn tyrosine kinase (Fig. 1A). Due to the established pivotal role of Lyn tyrosine kinase as a central signaling molecule (10) in mast cell activation by $\mathrm{IgE}-\mathrm{Ag}$, we concentrated on investigating this relationship. The specificity of the SPHK/Lyn interaction was notable, since this Ab array also harbors a variety of Abs to additional tyrosine kinases like Syk, Yes, and c-Src that are known to be expressed in mast cells (see Fig. 1A) (10). That these additional kinase-specific antibodies served as an appropriate specificity control for SPHK1/Lyn interaction was demonstrated by the fact that with the same Ab array, Syk protein and its phosphorylation after stimulation of BMMC is easily visualized (E. Bofill-Cardona, unpublished data). Longer exposures of the autoradiogram of the $\mathrm{Ab}$ array revealed the presumably weaker interaction of Fyn and Lck with SPHK1. This indicates a potential interaction of SPHK with these two kinases, which merits future exploration. Other kinases such as Blk, c-Fgr, Syk, c-Src, and c-Yes, however, showed no interaction upon longer exposures.

Because of the apparent strong interaction of SPHK with Lyn in the Ab array, we investigated if the initial findings reflected a direct interaction. This was accomplished by co-IP of in vitro transcribed and translated proteins (mLyn and mSPHK1). Due to the nearly identical molecular mass of the two recombinant proteins, resolution by SDS-PAGE was difficult (Fig. 1B, lane 1), thus we alternated the radiolabeling of one of the two in vitro transcribed and translated molecules in each of the reactions (Fig. 1B, lanes 2 to 7). The inverse IPs were done using, on the one hand, Ab to Lyn under conditions 
A

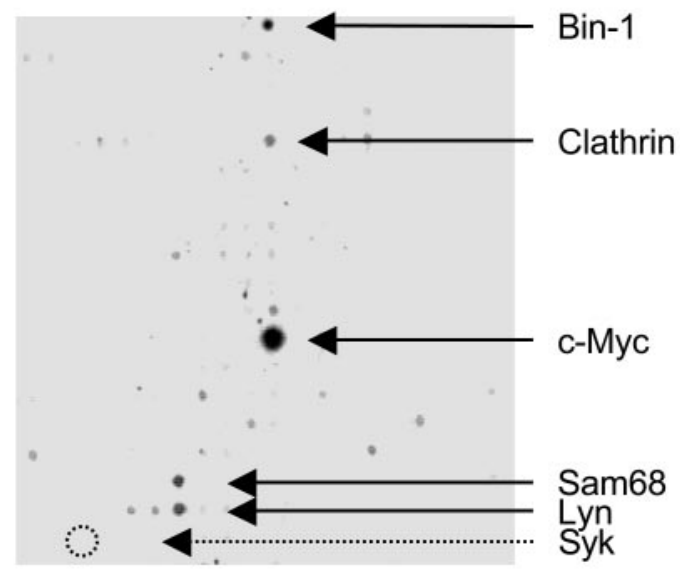

B
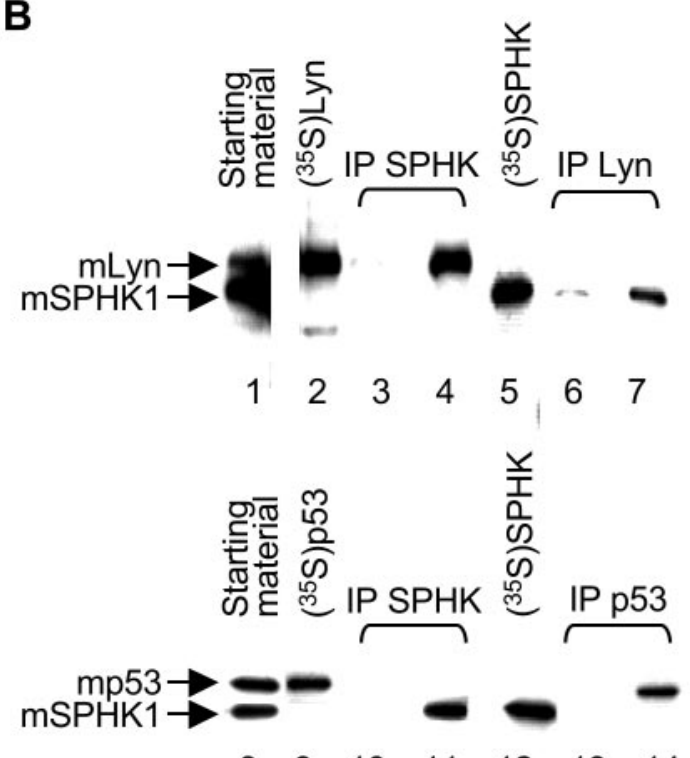

$\begin{array}{lllllll}8 & 9 & 10 & 11 & 12 & 13 & 14\end{array}$

FIG. 1. SPHK interacts with Lyn kinase in vitro. (A) Autoradiogram of an $\mathrm{Ab}$ array, showing mSPHK1 interacting proteins in IgEAg-stimulated BMMC. Proteins identified by this method are indicated to the right by solid arrows. c-Myc comprises a positive control $\mathrm{Ab}$, as it recognizes the radiolabeled myc-tagged mSPHK1 directly. The dotted circle and dotted arrow indicates the position of an $\mathrm{Ab}$ to Syk tyrosine kinase that serves as a specificity control for the detected interaction with Lyn kinase. (B) Top panel, co-IP of in vitro transcribed and translated mLyn and mSPHK1. Lane 1, starting materialradiolabeled mLyn and $\mathrm{mSPHK}$, indicated by the arrows to the left; lane 2, starting material-radiolabeled mLyn; lanes 3 and 4, co-IP of radiolabeled mLyn by an Ab directed to the myc tag of mSPHK1 in the absence (lane 3) or presence (lane 4) of unlabeled mSPHK1 (indicated by IP SPHK); lane 5, starting material-radiolabeled mSPHK1; lanes 6 and 7, co-IP of radiolabeled mSPHK1 by an Ab directed to Lyn in the absence (lane 6) or presence (lane 7) of unlabeled mLyn (indicated by IP Lyn). Shown is one representative experiment of a series of six. Bottom panel, specificity control where radiolabeled p53 is substituted for mLyn under identical conditions as above and IP of p53 or SPHK (both proteins are radiolabeled) is done. Lane 8, starting materialradiolabeled p53 and mSPHK1, indicated by the arrows to the left; lane 9, starting material-radiolabeled p53; lanes 10 and 11, co-IP of radiolabeled $\mathrm{p} 53$ by an $\mathrm{Ab}$ directed to the myc tag of mSPHK1 (radiolabeled) in the absence (lane 10) or presence (lane 11) of radiolabeled mSPHK1 (indicated by IP SPHK); lane 12, starting materialradiolabeled mSPHK1; lanes 13 and 14, co-IP of radiolabeled mSPHK1 where SPHK was radiolabeled (Fig. 1B, lanes 5 to 7), and on the other hand, an Ab to IP the myc tag of mSPHK1 in the presence of radiolabeled mLyn (Fig. 1B, lanes 2 to 4 ). It is obvious (Fig. 1B, lanes 4 and 7) that in both directions co-IP was achieved, demonstrating that the two proteins interact. It should also be noted that under the buffer conditions used to detect these interactions (or IPs), phosphorylation of mSPHK1 by Lyn or Lyn autophosphorylation was not detected (data not shown), showing that the interaction of these proteins does not require their phosphorylation. To verify the specificity of this interaction, the same Abs were used to IP from samples where the unlabeled proteins were omitted as a control for nonspecific IP of the radiolabeled proteins (Fig. 1B, lanes 3 and 6). Second, to demonstrate that this interaction is specific for Lyn and SPHK1, we performed an identical experiment whereby the tyrosine kinase Lyn was substituted with the anti-oncogene p53 (molecular mass identical to that of Lyn), which was also radiolabeled (like SPHK1) to allow its identification after IP. Figure 1B, lanes 8 to 14, shows the failure to co-IP p53 with Ab to SPHK and vice versa, demonstrating the specificity of the interaction between Lyn and SPHK1.

Next we studied this interaction in a cellular context by transient transfection of murine or human SPHK1 with mLyn into HeLa cells. Figure 2A (lanes 1 and 2) shows that the anti-myc tag $\mathrm{Ab}$, used to detect SPHK, and the anti-Lyn Ab did not cross-react with other proteins in the HeLa cell lysate. Adequate expression of both molecules was seen after $48 \mathrm{~h}$ of transfection (Fig. 2A, lanes 3 and 4). Both SPHK and Lyn were expressed simultaneously in HeLa cells (Fig. 2A, lane 5). By using this experimental setting, an IP of mLyn showed the co-IP of SPHK, with the specific enzymatic conversion of S to S1P as a sensitive assay for SPHK detection. As can be seen in Fig. 2B, a significantly enhanced enzymatic activity was coprecipitated with $\mathrm{Ab}$ to Lyn only when Lyn is cotransfected with mSPHK1 in HeLa cells (compare lanes 4 and 5, Fig. 2B). Since human SPHK1 cotransfected with mLyn gave similar results (Fig. 2C), this interaction is evolutionary conserved. The specificity of this highly sensitive assay was tested by coexpression of mp53 with mSPHK1. As can be seen by Western blotting (Fig. 2D, lanes 1 to 4 ), transfection of the corresponding expression plasmids of mp53 and mSPHK1 into the HeLa cells results in enhanced expression of both proteins. However, as expected from the in vitro results in Fig. 1B, SPHK activity was not enhanced beyond control levels in an IP of p53 (compare lanes 7 and 8, Fig. 2D). These data confirm the SPHK/Lyn interaction observed in the in vitro transcription and translation studies by demonstrating that this specific interaction is maintained in a cellular context.

Lyn kinase is essential for the normal phosphorylation of FceRI, which initiates IgE-dependent mast cell activation. Lyn kinase associates with the FceRI $\beta$-chain and is further recruited upon stimulation of this receptor. Therefore, we investigated whether Lyn might recruit SPHK to FcERI. We used a recently established genetically engineered HeLa cell line that

by an $\mathrm{Ab}$ directed to $\mathrm{p} 53$ (radiolabeled) in the absence (lane 13) or presence (lane 14) of radiolabeled p53 (indicated by IP p53). Shown is one representative experiment of a series of two. 
A

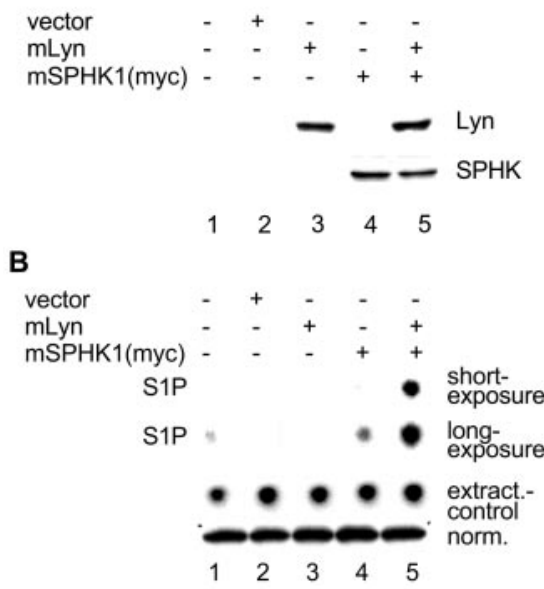

C

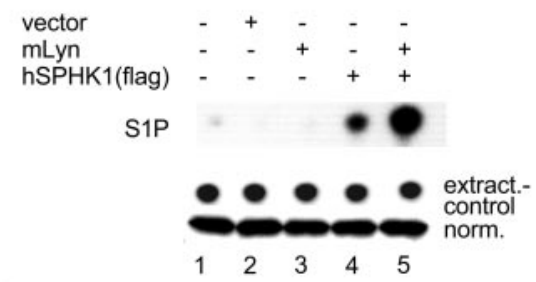

D

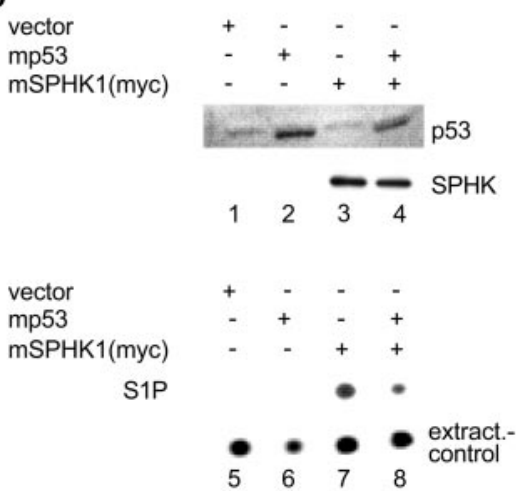

FIG. 2. Murine and human SPHK1 interact with mLyn in HeLa cells. (A) Western blot analysis of transfected HeLa cells. Transfection or no transfection with the plasmids shown on the left are indicated above the lanes $(+$ or -$)$. The $\mathrm{Ab}$ used for detection is shown on the right. (B) Co-IP of mSPHK activity by antiserum directed to Lyn from lysates of HeLa cells, transfected as described for panel A, as detected by an in vitro SPHK assay. Shown is an autoradiogram of a short or long exposure of a TLC plate showing the SPHK product S1P (as indicated). Fluram staining, which detects the primary amine of extracted $\mathrm{S}$, is used to normalize the equal extraction of lipids as shown and is labeled (extract.-control). Western blotting (norm.), which detects the amount of recovered protein G-Sepharose beads, is used to normalize for IP. (C) Same experimental setting as described for panel $\mathrm{B}$, but the mSPHK1 (myc-tagged) construct in the transfections was substituted by a construct for hSPHK1 (Flag tagged). (D) Top panel, Western blot analysis after transfection of HeLa cells using p53 instead of Lyn kinase as a specificity control for the above experiments. Bottom panel, SPHK activity in an IP of p53 after transfection of HeLa cells as a specificity control for the above experiments. Transfection conditions (A) were established and checked once for optimal expression, experiments shown in panels B to D are representatives out of a series of three.
A

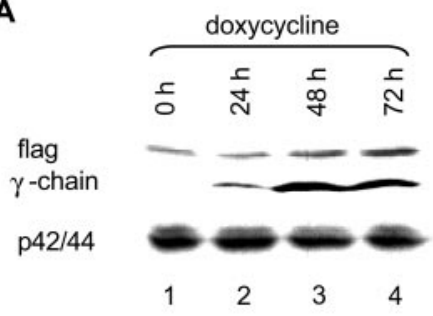

B

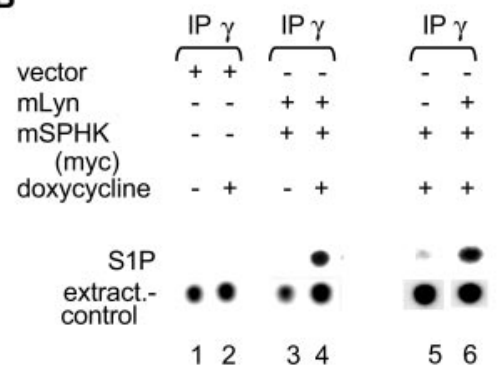

C

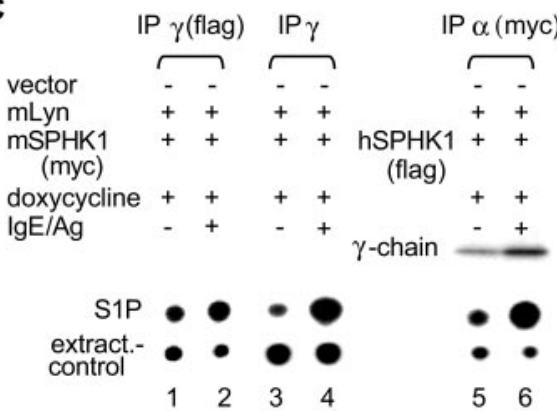

FIG. 3. Lyn recruits SPHK to the FceRI. (A) Western blot analysis, measuring hFceRI $\gamma$-chain induction in the recombinant HeLa cell line, using an anti-Flag tag $\mathrm{Ab}$ and antiserum directed to $\gamma$-chain (indicated to the left). As indicated, p42/44 Erk in cell lysates was used for normalization of protein concentration as detected by Western blot analysis. Time points of induction by doxycycline are shown above the lanes. (B) Co-IP of SPHK activity from lysates of transfected HeLa cells treated $(+)$ or not treated $(-)$ with doxycycline to induce FceRI $\gamma$-chain expression. The FceRI IP was with Ab to FceRI $\gamma$ (as indicated) and was coupled to an in vitro SPHK assay. Input plasmids are indicated to the left, and also indicated is whether they were used $(+)$ or not $(-)$. Shown is an autoradiogram of a TLC plate. S1P on the TLC plate is indicated. As in Fig. 2, Fluram staining, normalizing for the equal extraction of lipids (extract.-control, indicated to the left), is shown. Induction of the FceRI $\gamma$-chain was for 48 to $72 \mathrm{~h}$, as shown in panel A, lanes 3 and 4. (C) Co-IP of SPHK activity from lysates of transfected and $\mathrm{IgE}-\mathrm{Ag}$-stimulated $(+)$ or nonstimulated $(-) \mathrm{HeLa}$ cells with Ab or antiserum to Flag (of FceRI $\gamma$, lanes 1 and 2) or $\gamma$-chain directly (lanes 3 and 4) or myc tags (of FceRI $\alpha$, lanes 5 and 6) as indicated. IPs were coupled to an in vitro SPHK assay. The modest increase in FceRI $y$ seen in lane 6 was not reproducible in other experiments. Time kinetics of expression (A) were determined once; experiments in panels $\mathrm{B}$ and $\mathrm{C}$ are representatives out of a series of four.

harbors the human $\gamma$-chain (fused to a Flag tag), with its expression being inducibly controlled by a doxycycline-dependent promoter (1). In addition, this cell line expresses the human FceRI $\alpha$ - (myc-tagged) and $\beta$-chain, but only upon $\gamma$-chain induction can the tetrameric FceRI be expressed on the cell surface (1). This allowed us to investigate the relation- 
ship between cell surface expression of FceRI and its association with Lyn and SPHK in a cell system that is normally devoid of surface FceRI or Lyn expression. Figure 3A shows the kinetics of FceRI $\gamma$ induction by doxycycline; its expression was detected (by anti-FLAG or anti- $\gamma \mathrm{Ab}$ ) within $24 \mathrm{~h}$, peaking at $48 \mathrm{~h}$ postinduction and remaining relatively unchanged through $72 \mathrm{~h}$. Subsequent experiments employed cells 48 to $72 \mathrm{~h}$ postinduction and conditions of low detergent concentrations for cell solubilization to favor FceRI subunit association. Transient transfection of these cells, either induced to express FceRI $\gamma$ or not, with mSPHK1 alone or in combination with mLyn showed that SPHK activity was coprecipitated with Ab to FceRI $\gamma$ only when the $\gamma$-chain is induced by doxycycline (Fig. 3B, lanes 3 and 4). This coprecipitated SPHK activity was also dependent on the presence of Lyn kinase, since SPHK activity was only detected when mLyn was cotransfected (compare lanes 5 and 6, Fig. 3B). This shows that Lyn is required for the co-IP of SPHK activity with FceRI, thus eliminating the possibility that IP of FceRI caused the nonspecific co-IP of SPHK.

We next investigated whether a direct functional relationship between FceRI, Lyn, and SPHK might exist by assessing whether increased SPHK activity occurs upon FceRI stimulation. This might also reveal whether Lyn/SPHK1 binding to FceRI is directly linked to the described increase of SPHK activity after FceRI stimulation. However, it had to be considered that in this heterologous HeLa system, FceRI stimulation might fail to increase SPHK activity because of the absence of the appropriate signaling molecules in this cell. Nonetheless, as seen in Fig. 3C, IgE-Ag caused an additional increase of FceRI-associated SPHK1 activity in the HeLa cells that was similar to that seen in IgE-dependent mast cell activation. Stimulation of FceRI (Fig. 3C, even lanes) clearly enhanced the receptor-associated lipid kinase activity that was coimmunoprecipitated with FceRI (compare anti-Flag IP [lanes 1 to 2] and anti- $\gamma$-chain IP [lanes 3 to 4]). To ensure that the observed $\mathrm{IgE}-\mathrm{Ag}$-dependent increase in SPHK activity was indeed FceRI specific (since the FceRI $\gamma$ is shared with mast cellexpressed Fc $\gamma$ RIII), we first exchanged the mSPHK1 construct (myc tagged) for the human version (hSPHK1, Flag tagged), which allowed the IP of the stably expressed FceRI $\alpha$-chain (that was myc tagged) and measurement of any associated SPHK activity. As seen in Fig. 3C (lanes 5 and 6), the FceRI $\alpha$-associated SPHK activity was strongly increased upon IgE-Ag stimulation (approximately fourfold). That the intact FceRI was successfully immunoprecipitated (under the low detergent solubilization conditions used) is demonstrated by probing with $\mathrm{Ab}$ to the $\gamma$-chain. While in this experiment a modest increase (1.5-fold) in the detected $\gamma$-chain was observed after FceRI stimulation, this was variable among experiments, whereas the SPHK activity was always increased. Together, with the data shown in Fig. 3B, the findings provide a clear demonstration of the Lyn-dependent recruitment of SPHK to the FceRI and show that SPHK activity is increased in an FceRI stimulation-dependent manner (see also Fig. 7).

To further explore the question of whether Lyn and SPHK interact directly, we used highly purified (one band on a silverstained SDS-PAGE; Fig. 4, left panels) hSPHK1 and hLyn in co-IP experiments. As seen in the corresponding SPHK assay, considerable SPHK1 activity was detected by co-IP, with Ab to
A

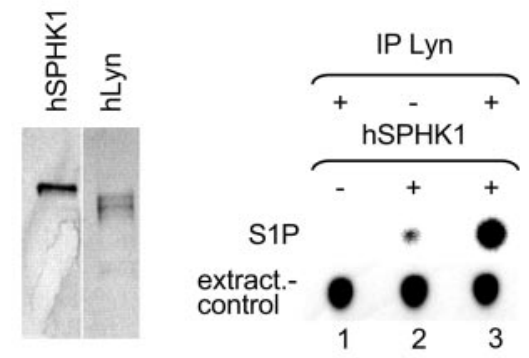

B

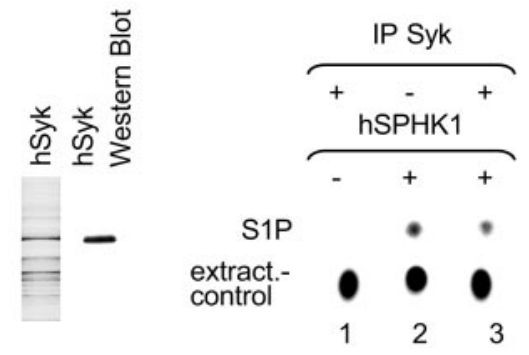

C

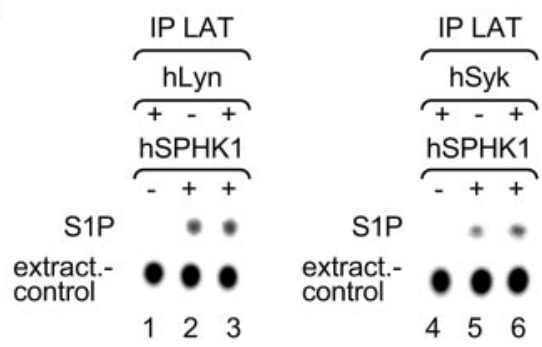

FIG. 4. SPHK directly binds to Lyn. (A) Left panel, silver-stained SDS-PAGE of the highly purified proteins as indicated above the lanes (hSPHK1 and hLyn); right panel, co-IP of hSPHK1 (activity) by an Ab to Lyn (indicated by IP Lyn) in the absence (-) of hSPHK1 (lane 1), in the absence of hLyn (lane 2$)$, and in the presence $(+)$ of both proteins (lane 3). An autoradiogram of a TLC plate is shown. The position of S1P on the TLC plate is indicated and Fluram staining is used to normalize for the equal extraction of lipids (extract.-control, indicated to the left). The concentration of hLyn used was $160 \mathrm{nM}$, the concentration of hSPHK1 used was $7 \mathrm{nM}$. (B) Left panel, silver-stained SDS-PAGE of a highly enriched baculovirus-expressed Syk and corresponding Western blot analysis to Syk as indicated; right panel, same experimental conditions as in panel A except that Lyn kinase was replaced with Syk kinase (see above). (C) Specificity control for hSPHK1 for panels A and B (see above) using the same experimental conditions. Ab to LAT was used to IP the mixtures where SPHK was incubated $(+)$ with Lyn (left panel) or Syk (right panel) or from reactions where hSPHK1 or hLyn was absent $(-)$ (lanes 1 and lane 2, respectively). Experiments in panels $\mathrm{A}$ and $\mathrm{B}$ were repeated three times, and the experiment in panel $\mathrm{C}$ was done twice.

Lyn, only when Lyn was present in the reaction, demonstrating a direct interaction between both molecules (compare lanes 2 and 3, right panels, Fig. 4). The specificity of the molecular interaction of these two proteins was demonstrated by substituting, for Lyn kinase, a highly enriched baculovirus-expressed preparation of Syk kinase (Fig. 4B). The findings show that IP with $\mathrm{Ab}$ to Syk failed to show any difference in detected SPHK activity whether Syk was present or not (Fig. 4B, lanes 2 and 3). This is consistent with the failure to detect SPHK interaction 
A

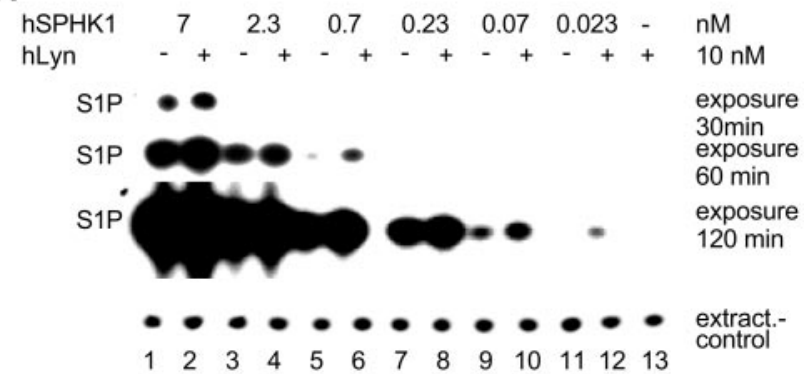

B

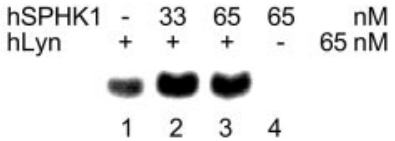

C

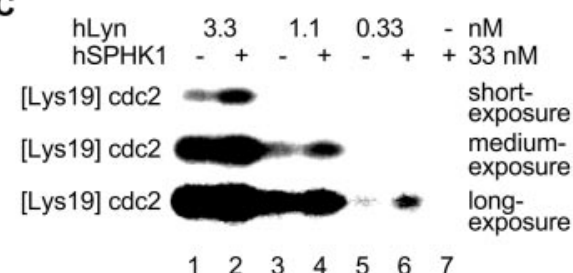

D

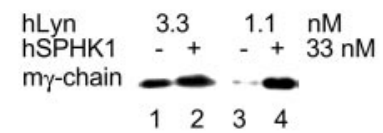

E

$\begin{array}{lllllll}\text { hSPHK1 } & 7 & 2.3 & 0.7 & 0.23 & -\mathrm{nM}\end{array}$

hc-Jun $-++-+++10 \mathrm{nM}$

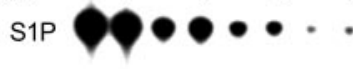

- - - - $-\bullet$ extract.-

$\begin{array}{lllllllll}1 & 2 & 3 & 4 & 5 & 6 & 7 & 8 & 9\end{array}$

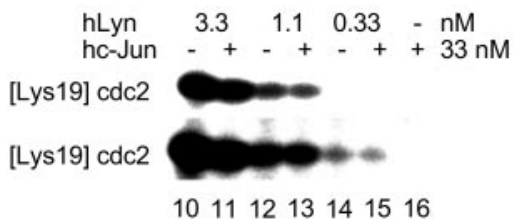

FIG. 5. Lipid and tyrosine kinase activities are enhanced in an SPHK/Lyn complex. (A) SPHK activity was assayed with different concentrations of purified hSPHK1 (as indicated on the top [nM]) either alone (uneven lanes; -) or in the presence of purified hLyn kinase $(10 \mathrm{nM}$, even lanes; +). Shown are different autoradiogram exposures of a TLC plate used for separation of S1P (exposure time indicated to the right). Fluram stainings used for normalizing extraction of lipids (extract.-control, indicated to the right). (B) Autophosphorylation assay (in vitro kinase assay) of purified hLyn either alone (lane 1) or in a complex with two different concentrations of purified hSPHK1 protein as indicated (lanes 2 and 3). (C) Phosphorylation assay (in vitro kinase assay) of purified hLyn either alone (uneven lanes; - ) or in a complex with purified ( $33 \mathrm{nM})$ hSPHK1 protein (even lanes; +) using a peptidic substrate ([Lys19] cdc2, indicated to the left). Autoradiogram exposure times are indicated to the right. Concentrations of hLyn protein are indicated above the lanes. (D) Phosphorylation assay (in vitro kinase assay) of purified hLyn, at indicated concentrations, either alone (uneven lanes; -) or in a complex with purified hSPHK1 protein (even lanes; + ) on mFceRI $\gamma$-chain as a substrate. mFceRI $\gamma$-chain was isolated by IP from murine CPII mast cells, and identical aliquots of the IP were used as a substrate in this with Syk by Ab array methodology (compare also Fig. 1A and 4B). To further verify the specificity of the Lyn Ab, the experiments in Fig. 4A and B were repeated using an Ab to LAT. These experiments showed that $\mathrm{Ab}$ to LAT failed to co-IP increased SPHK activity in the presence or absence of either Lyn or Syk. Whereas low background SPHK1 activity was immunoprecipitated with Ab to LAT, the addition of hLyn or hSyk in the reaction failed to increase the SPHK1 activity that was immunoprecipitated with anti-LAT (Fig. 4C, lanes 1 to 6). This demonstrated that increased SPHK1 activity is detected only under conditions where Lyn is specifically immunoprecipitated, proving the direct interaction of these purified recombinant proteins.

The findings so far demonstrate that Lyn and SPHK1 interact, that the Lyn/SPHK complex is recruited to FceRI, and that IgE-Ag cross-linking of FceRI caused increased FceRI-associated SPHK1 activity. Thus, we wished to address the functional consequence of Lyn/SPHK1 interaction. Specifically, we aimed to explore whether the interaction of these proteins resulted in increased or decreased activity of one or both. To accomplish this goal we utilized highly purified recombinant Lyn and SPHK1, which were allowed to form a complex in vitro. Preliminary enzymatic assays using serial dilutions (3.3-fold) established concentrations of these proteins in which enzyme kinetics were linear (data not shown). Figure 5A shows that the SPHK1 activity was significantly stimulated when hLyn was added to the reaction to form a complex. This contrasted with the reduced SPHK1 activity in the absence of hLyn. Particularly, at low concentrations of SPHK1 alone (0.023 nM), SPHK1 activity was not observed but was detected only upon addition of hLyn (Fig. 5A, lanes 11 and 12). It is noteworthy that phosphorylation of hSPHK1 by hLyn was not observed (data not shown). By using similar assay conditions, the autophosphorylation of Lyn kinase (Fig. 5B, lanes 1, 2, and 3) and its activity as measured by phosphorylation of a peptidic substrate (Fig. 5C, lanes 1 to 2, 3 to 4 , and 5 to 6) and phosphorylation of $\gamma$-chain (Fig. 5D, lanes 1 to 2 and 3 to 4 ) were also significantly enhanced. To show that the stimulation of lipid (SPHK1) and tyrosine (Lyn) kinase activities was not simply due to a protein concentration effect, the experiments represented in Fig. 5A and $\mathrm{C}$ were repeated, but identical concentrations of highly purified c-Jun protein were substituted for hLyn (Fig. 5E, top panel) or for hSPHK1 (Fig. 5E, bottom panel). In neither case did the substitution of c-Jun result in enhancement of the respective activities (Lyn and SPHK1, Fig. 5E, lanes 7 and 8 or 14 and 15). This confirmed that the increased activity of Lyn and SPHK1 is a result of the specific interaction between the two kinases.

Upon FceRI engagement, additional recruitment of Lyn kinase into lipid raft domains has been observed (11). This coincides with the movement of FceRI into these domains (11,

assay. Panels B to D are autoradiograms of fixed and dried SDS-PAGE and peptide gels. (E) Top panel, specificity control using hc-Jun instead of Lyn kinase using identical experimental conditions as in panel A; bottom panel, inverse experiment where c-Jun is substituted for hSPHK1 and hLyn kinase activity is measured as in panel C. Experiments in panels A to E were done at least three times (between three and six), and one representative example is shown. 
A

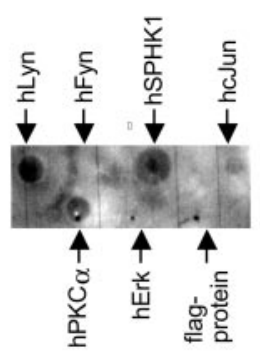

B

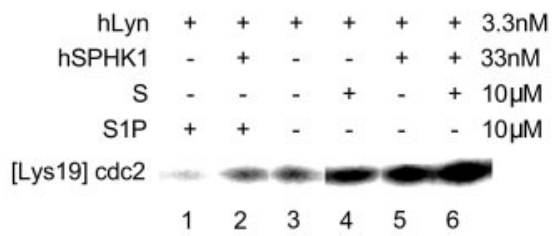

hLyn $+\quad+\quad+3.3 \mathrm{nM}$
Galac.S $-+\quad-10 \mu \mathrm{M}$
Gluco.S $-\quad+\quad+10 \mu \mathrm{M}$
[Lys19] cdc2

$\begin{array}{lll}7 & 8 & 9\end{array}$

C

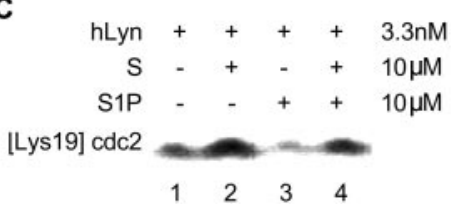

FIG. 6. Influence of SPHK, S, and S1P on Lyn activity. (A) Lyn is an S-binding protein; S-binding dot blots using $\left[{ }^{3} \mathrm{H}\right] \mathrm{S}$ and the indicated membrane-bound purified proteins. An autoradiogram is shown. The failure of hc-Jun, hFyn, hErk, and Flag protein to bind S serves as a negative control. This experiment was repeated three times. (B) Top panel, phosphorylation assay of hLyn either alone or in a complex with purified hSPHK1 protein in the presence $(+)$ and absence $(-)$ of S or S1P (as indicated to the left and above the lanes) using a peptidic substrate ([Lys19] cdc2). Concentrations are shown to the right; bottom panel, phosphorylation assay of hLyn either alone (lane 7) or with two additional lipids (galactosylsphingosine, lane 8; glucosylsphingosine, lane 9) as a specificity control for S/S1P effects. (C) Same experiment as in panel B (top panel) showing the inhibitory and dominant effect of S1P on Lyn activity when S and S1P are simultaneously added to the reaction. Experiments under panels B and C are representatives of a series of five and two repetitions.

12). Lyn recruitment into these domains can be influenced by treatment of mast cells with exogenous sphingolipids (38), demonstrating the importance of sphingolipids to these specialized domains. Since sphingolipids can be metabolized to generate S, the substrate of SPHK1, we investigated whether S itself might also interact with Lyn and influence its activity. As seen in Fig. 6A, dot blots to assess $\mathrm{S}$ binding revealed that Lyn kinase can bind $\mathrm{S}$ with an affinity comparable to known $\mathrm{S}$ binders such as SPHK and PKC. This interaction is specific since the highly homologous hFyn kinase and other cell signaling proteins like hErk and hc-Jun failed to bind the radiolabeled S. These data strongly support the notion that Lyn kinase activity might be regulated by changes in the S:S1P content. Therefore, we investigated the influence of S and S1P on Lyn activity when Lyn is present alone or in a complex with SPHK. Figure 6B, lanes 3 and 5, once again demonstrate the influence of SPHK/Lyn complex formation in increasing Lyn activity as measured by phosphorylation of a peptidic substrate. Interestingly, the addition of S to Lyn alone (Fig. 6B, lanes 3 and 4) also caused increased Lyn kinase activity. Moreover, the enhancement of Lyn kinase activity by $\mathrm{S}$ is further augmented when SPHK is present (Fig. 6B, lanes 5 and 6). This shows that $\mathrm{S}$, which is the substrate for SPHK, has a positive influence on the Lyn/SPHK complex activity. In contrast, S1P has a negative influence on the kinase activity of Lyn (Fig. 6B, compare lanes 3 to 1 and 5 to 2). While there is a slight increase of Lyn activity when complexed to SPHK in the presence of S1P (Fig. 6B, lanes 1 to 2), this increase is minimal compared to the activity seen in the absence of S1P (Fig. 6B, lanes 2 to 5). That the stimulatory effect of $\mathrm{S}$ on Lyn kinase activity is specific and not an effect of lipids in general is further demonstrated by the fact that closely related derivatives of $\mathrm{S}$ (galactosyl- and glucosyl-S) that have a higher tendency to form micelles failed to enhance Lyn kinase activity (Fig. 6B, lanes 7 to 9). Furthermore, $\mathrm{S}$ is already known to specifically stimulate casein kinase II, epidermal growth factor receptor kinase, and 3-phosphoinositide-dependent kinase 1. Thus, we now can add Lyn kinase to the growing list of molecules for which $\mathrm{S}$ is a positive effector $(8,18,22,23)$. In the general context of the rheostat hypothesis, these data suggest that binding to SPHK and/or S directly activates Lyn while the SPHK-mediated local change from nonphosphorylated to phosphorylated (S to S1P) sphingolipids might comprise a negative feedback loop in Lyn activation. To further explore this feedback hypothesis, we repeated the above experiment but instead added S and S1P simultaneously, as inhibition by S1P of Lyn activity would be expected to be dominant if the negative feedback hypothesis was viable. As seen in Fig. 6C (compare lanes 1 and 2 for the $S$ induction and lanes 2 to 4 for the effect of S1P on S induction), the S-enhanced Lyn activity is downregulated by S1P. Upon the simultaneous addition of S and S1P, the activity of Lyn is similar to that seen in the absence of S. This strongly supports the proposed hypothesis of regulatory control of Lyn activity by these two sphingolipids.

Based on the aforementioned data, one might expect that both Lyn and SPHK activities might be enhanced in the lipid raft domains. For Lyn kinase, this was recently demonstrated by the study of Young and colleagues (51), which showed increased Lyn kinase activity in these domains and changes in the phosphorylation of the regulatory tyrosines of Lyn that favored phosphorylation of the activation loop tyrosine. However, whether SPHK activity is increased in lipid rafts is not known. We first assessed the overall cellular localization of SPHK activity. BMMC lysates were fractionated by low-salt (highly soluble proteins), higher-salt (less-soluble cytoplasmic proteins), and Triton extraction (membrane proteins). As is shown in Fig. 7A (left panel), about $95 \%$ of SPHK activity is found in the low-salt cytoplasmic fraction, while only 5\% localizes in the membranes (Triton fraction; identical distribution was seen for the endogenous and transfected SPHK1 activity). However, the increased SPHK activity after IgE-Ag is more prominent in the membrane fraction (compare lane 3 in the top and bottom panels). We next investigated whether and how much of this activity can be found in isolated lipid rafts 
A

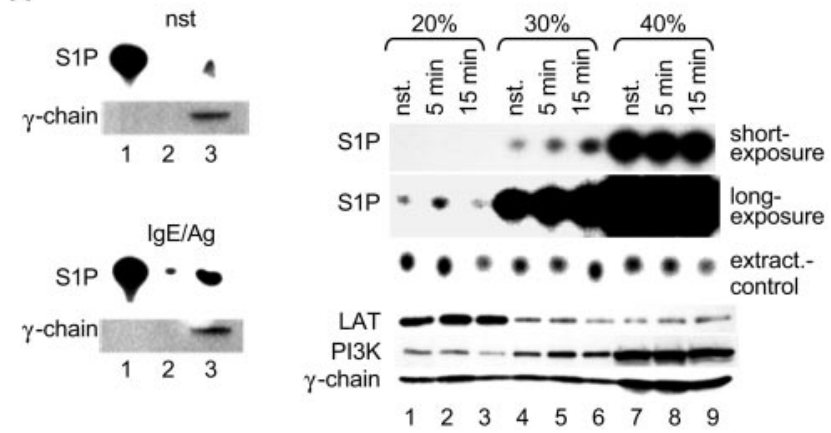

B
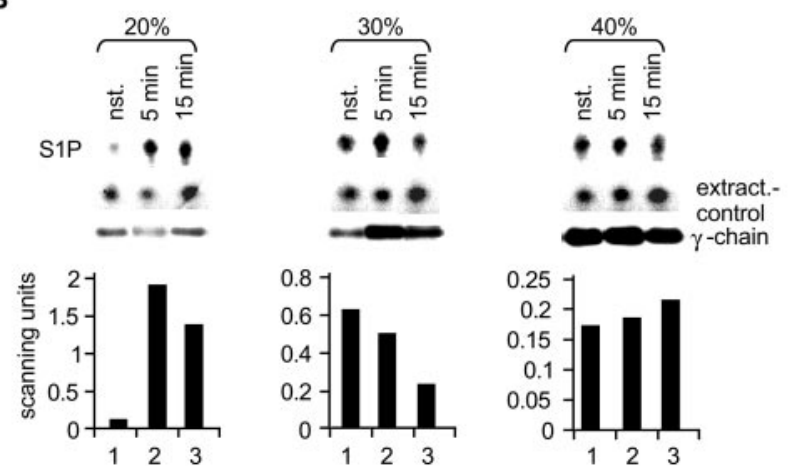

FIG. 7. SPHK can be found within lipid rafts where it is FceRI associated and activated by IgE-Ag. (A) Left panel, fractionation of BMMC extracts and SPHK activity assays of a low-salt (lane 1), highsalt (lane 2), and Triton-extractable (lane 3 ) fraction to crudely determine the cytoplasmic and membrane localization of the activity in unstimulated (nst; top panel) and $\mathrm{IgE}-\mathrm{Ag}$-stimulated (bottom panel) cells. A Western blot analysis of the $\gamma$-chain is shown, indicating successful isolation of membrane proteins. Right panel, SPHK activity assay of the raft fraction (20\%) and the 30 and $40 \%$ fractions (as indicated) for mSPHK1-transfected CPII mouse mast cells, unstimulated (nst) and activated by IgE-Ag for the indicated time. Shown is an autoradiogram of a TLC plate. Production of S1P is shown at two different exposure times as indicated. Fluram staining is used to normalize for the equal extraction of lipids (extract.-control). Western blotting for LAT, PI3K, and FceRI $\gamma$-chain shows the successful partitioning of lipid rafts and the distribution of the receptor in the sucrose gradient. (B) IP of FceRI $\gamma$-chain from lipid rafts (20\% sucrose fraction) of unstimulated (nst) or IgE-Ag-stimulated BMMC (at indicated times) and from the 30 and $40 \%$ sucrose fractions. IPs were coupled to an in vitro SPHK assay. Shown is an autoradiogram of a TLC plate. Production of S1P on the TLC plate is indicated. Fluram staining is used to normalize for the equal extraction of lipids (extract.control), and Western blot analysis of FceRI $\gamma$-chain is used to normalize for IP. Densitometric quantitation of SPHK activity normalized to immunoprecipitated FceRI $\gamma$-chain is shown as a bar graph. All experiments were done at least three times; one representative example is shown.

from nonstimulated and 5-min- and 15-min-IgE-Ag-stimulated CPII mouse mast cells. As seen in Fig. 7A (right panel, compare lanes 1 and 2), an increase in SPHK activity is observed 5 min after stimulation in the raft fraction $(20 \%$ fraction). Some increase in activity was, however, also found in the $30 \%$ fraction (compare lanes 4 and 5, which may potentially contain some light density membranes). Additionally, this mirrored a modest increase (1.3-fold in this experiment) of FceRI $\gamma$-chain in the lipid raft fraction $(20 \%)$ and also in the $30 \%$ sucrose fraction (Fig. 7A, compare lanes 1 to 2 and 4 to 5).
Successful partitioning of lipid rafts is shown by the relative distribution of the known lipid raft resident protein, LAT, and the minor presence of the p85 regulatory subunit of PI3K, as well as the relative distribution of FceRI prior to and after stimulation with $\mathrm{Ab}$ to the $\gamma$-chain (Fig. 7A).

To further confirm this finding, we repeated these experiments using primary BMMC (Fig. 7B). If we specifically measured the FceRI-associated SPHK activity by $\gamma$-chain IPs from the different sucrose fractions and normalized it to $\gamma$-chain content of the IPs, an induced SPHK activity is predominant in the lipid rafts $(20 \%)$ after 5 and 15 min of stimulation (Fig. 7B, compare lanes 1 and 2). While in some experiments a minor induction was also seen in the $30 \%$ fraction, this was variable and entirely dependent on the level of SPHK activity observed in the nonstimulated control (Fig. 7A, compare lanes 4 and 5). Nonetheless, in repeated experiments this induction was not statistically meaningful with respect to FceRI-associated SPHK activity (Fig. 7B, 30\% fraction quantitation). Therefore, BMMC specifically show a strong induction (up to 10-fold) of FceRI-associated SPHK activity in the $20 \%$ fraction after stimulation by IgE-Ag (Fig. 7B, bottom left panel). In contrast, no increase in FceRI-associated SPHK activity is detected in the other fractions (Fig. 7B, middle panel and right panel).

These results suggest that the IgE-Ag activation of mast cells should cause an increase in Lyn-associated SPHK activity that might also be detected by Lyn IP. To test this possibility we stimulated BMMC with IgE-Ag, and endogenous Lyn was isolated by IP and assayed for SPHK activity. As shown in Fig. 8A (lanes 1 and 2) 1 min of stimulation by IgE-Ag led to an almost fivefold increase in Lyn-associated SPHK activity. In contrast, the IP of LAT, which is also lipid raft localized (Fig. 7A), under identical conditions showed minimal SPHK activity and no induction upon FceRI stimulation (Fig. 8A, lanes 3 and 4, see bar graph for quantitation). This demonstrates that the observed SPHK and Lyn interaction and its regulatory control on SPHK activation upon IgE-Ag stimulation is not just merely a consequence of co-IP of proteins colocalized to lipid raft domains. Moreover, it demonstrated that SPHK is functionally associated with Lyn in a cellular context. To further test the importance of Lyn to SPHK1 activity, BMMC were derived from $\mathrm{Lyn}^{-1-}$ and syngeneic wild-type mice and the kinetics of SPHK1 activity was measured. Buffer conditions used in the graph shown in Fig. 8B were selective for SPHK1 (for conditions, see reference 4) since this isoform was the focus of our in vitro studies. However, it should be noted that BMMC express mRNA for both SPHK1 and SPHK2 (16; also D. Mechtcheriakova, unpublished data). Figure 8B shows the biphasic stimulation (shown as $n$-fold induction) of SPHK1-dependent lipid kinase activity in mast cells derived from wildtype mice. Exhaustive analysis faithfully reproduced this profile of SPHK1 activation. In comparison, mast cells derived from $\mathrm{Lyn}^{-1-}$ mice clearly lacked the first (early) peak of SPHK1 activity. This finding was consistent in all experiments, and the differences were highly significant (six to eight experiments, $P$ $<0.0001$ ). Moreover, the basal SPHK1 activity in wild-type and $\mathrm{Lyn}^{-1-}$ cells did not differ significantly (Fig. 8B, bottom panel, $0 \mathrm{~min}$ ). In contrast, upon IgE-Ag stimulation the induction of SPHK1 activity in $\mathrm{Lyn}^{-1-}$ BMMC was significantly delayed compared to wild-type cells (Fig. 8B, bottom panel, 0.5 and $10 \mathrm{~min}$ ). Further fractionation to recover primarily mem- 
A

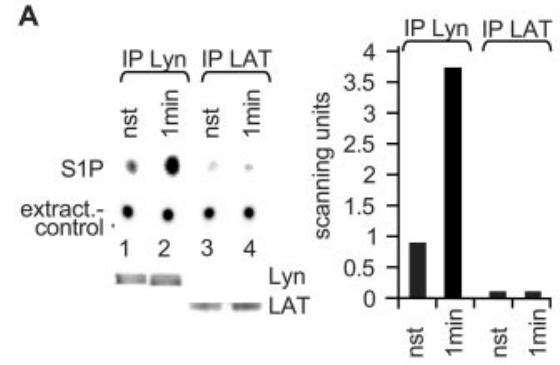

B

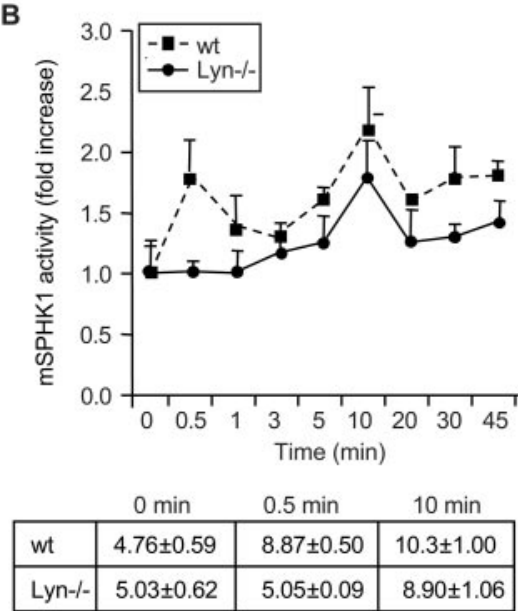

C

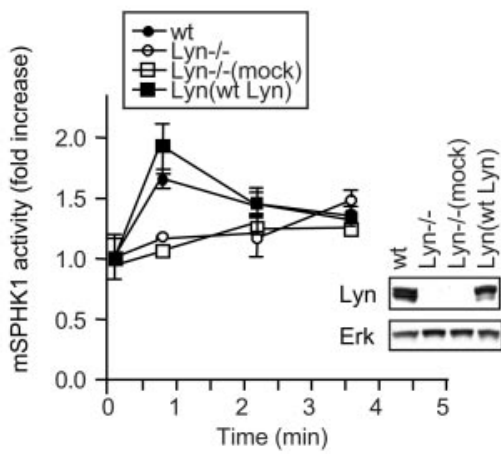

FIG. 8. Induction of SPHK activity and specific interaction with Lyn kinase in BMMC from wild-type and $\mathrm{Lyn}^{-1-}$ mice. (A) Left panel, co-IP of SPHK activity by antisera directed to Lyn and LAT (used as negative control) from lysates of primary BMMC (nonstimulated [nst] and stimulated by $\mathrm{IgE}-\mathrm{Ag}$ for $1 \mathrm{~min}$ ) coupled to an in vitro SPHK assay. Shown is a representative autoradiogram of a TLC plate done twice. Production of S1P was measured on a TLC plate as shown. Fluram staining was used to normalize for the equal extraction of lipids (extract.-control) and a Western blot analysis, controlling for equal IP of endogenous expressed Lyn and LAT, is also shown. Right panel, bar graph shows densitometric quantitation of normalized SPHK activity coimmunoprecipitated with Lyn or LAT. (B) BMMC from $\mathrm{Lyn}^{-1-}$ mice are defective in the early rise of SPHK1 activity after IgE-Ag triggering. Kinetics of SPHK1 activity induced by IgE-Ag triggering of mast cells from wild-type (wt) and $\mathrm{Lyn}^{-1-}$ mice (shown as $n$-fold induction equal to relative levels of activity). Data represent the means \pm standards deviations of six to eight independent experiments. The table shown in the bottom panel gives the absolute SPHK activity $(\mathrm{pmol} / \mathrm{min} / \mathrm{mg})$ at basal $(0 \mathrm{~min})$, early peak $(0.5 \mathrm{~min})$, and late peak of activity (10 min). (C) Reintroduction of Lyn kinase in BMMC from $\mathrm{Lyn}^{-1-}$ mice reestablishes the $\mathrm{IgE}-\mathrm{Ag}$-induced increase in the early phase of SPHK1 activity. Kinetics of IgE-Ag-induced SPHK1 activity in wild-type BMMC (wt) or that after reintroduction of wild-type Lyn into $\mathrm{Lyn}^{-1-}$ BMMC (wt Lyn) are shown; nontransduced $\mathrm{Lyn}^{-1-}$ branes confirmed the induction of SPHK1 activity in membranes, in line with previous findings by Melendez and Khaw (25). However, the relative level of SPHK1 induction in BMMC membranes was much less than that observed by Melendez and colleagues in human mast cells (Fig. 7A; also A. Olivera, unpublished data).

If indeed early SPHK1 activity is Lyn dependent, one might expect reconstitution of this early phase by reintroduction of Lyn. $L y n^{-/-}$BMMC were reconstituted with wild-type Lyn by retroviral expression (Fig. 8C, inset). As control, $\mathrm{Lyn}^{-/-}$ $\mathrm{BMMC}$ were transduced with retrovirus alone (mock). Analysis of total SPHK1 activity demonstrated that reintroduction of Lyn restores the early SPHK1 activity that is defective in $L y n^{-1-}$ BMMC (Fig. 8C). The SPHK1 activity in mock-transduced cells mirrored the activity seen in $\mathrm{Lyn}^{-1-}$ BMMC. These findings demonstrate the importance of Lyn kinase in the early activation of SPHK1 and support the proposed model of Lyndependent SPHK1 activation.

\section{DISCUSSION}

The identification of SPHK activation in the IgE-Ag-triggered mast cell analog, RBL-2H3 cells, by Choi et al. suggested that this was an early event that governed $\mathrm{Ca}^{2+}$ mobilization and was independent of PLC $\gamma$-mediated $\mathrm{Ca}^{2+}$ mobilization (7). Melendez and Khaw recently extended these studies by demonstrating that in mast cells translocation of SPHK1 could occur rapidly (1 $\mathrm{min}$ ) following $\mathrm{IgE}-\mathrm{Ag}$ stimulation and that SPHK1 activity was associated with the major increase in intracellular $\mathrm{Ca}^{2+}$ and was linked to mast cell degranulation (25). Based on these findings, the activation of SPHK activity in mast cells is likely to be a very early event, preceding PLC $\gamma$ and classical and novel PKC activation. While it is logical that the cytoplasmic-localized SPHK has to be brought to its substrate(s) at the cell membrane (25), this movement must occur quickly, given the early peak (0.5 to $3 \mathrm{~min})$ we observed in BMMC. In contrast, the late peak (15 to $20 \mathrm{~min}$ ) of SPHK1 activity correlates well with the kinetics of the PKC-dependent translocation described in HEK 293 cells (15). Regardless, it should be noted that our studies in BMMC showed that only a small fraction of the total cellular SPHK1 was found to translocate at early times to the plasma membrane $(\sim 5 \%)$. This differs from the results of Melendez and Khaw in human mast cells (25) but is quite consistent with the amount of Lyn associated with FceRI in stimulated cells (50).

Our findings of an interaction of SPHK1 with Lyn links SPHK activation to a primary tyrosine kinase phosphorylation and activation event and therefore places SPHK proximal to FceRI. The known kinetics of Lyn-dependent molecular activation in mast cells (i.e., Syk activation) are in very good agreement with the observed first peak of SPHK1 activation in the BMMC. Furthermore, in support of a functional interaction with Lyn, we find that the early phase of SPHK1 activity is absent in $\mathrm{Lyn}^{-/-}$mast cells, which also have a markedly delayed and reduced $\mathrm{Ca}^{2+}$ activation $(17,27,33)$. Surprisingly,

BMMC and vector only transduced $\mathrm{Lyn}^{-/-}$BMMC (mock reconstituted) are controls. Data represent means \pm standard deviations of three experiments. 
mast cells from $\mathrm{Lyn}^{-1-}$ mice do not show an impairment in degranulation $(17,27,33)$. This disconnect between the proposed (25) association of SPHK activation and $\mathrm{Ca}^{2+}$ rise and degranulation is at first glance contradictory to the reported effects of antisense oligonucleotides against SPHK1, which abolished degranulation (25). However, our findings of an enhanced PI3K/PKC $\delta$ activity along with increased Fyn activity in $\mathrm{Lyn}^{-/-}$mast cells might compensate for the loss of Lyn/SPHK activity (33).

The mechanism of activation of SPHK activity seemingly requires two steps. First, SPHK activity is directly increased by binding to Lyn. This effect is independent from additional cofactors or auxiliary proteins, as the experiments with purified components demonstrated. Furthermore, SPHK activation is independent of tyrosine phosphorylation by Lyn, as this was not detected in vitro or in cellular analysis. This argues that the interaction of SPHK with Lyn most likely induces conformational changes in the SPHK molecule that increase its activity (i.e., generating larger hydrophobic pockets, further substrate binding sites, etc.). The finding that Lyn is an S-binding protein is highly suggestive of this possibility, as it might be expected that SPHK interaction with Lyn-bound S would induce substrate and pseudosubstrate conformational changes because of the availability of substrate. In this scenario, the initial interaction of SPHK with Lyn might provide an increased local concentration of this substrate around Lyn-bound SPHK, facilitating its activation. The second step for increased SPHK activity is its targeting to the appropriate regions in the membrane where $\mathrm{S}$ is available. Lyn is known to exist and be further recruited into sphingolipid-enriched lipid rafts prior to and after mast cell activation, respectively $(11,12)$. It is plausible that plasma membrane-localized Lyn binds SPHK in, or comigrates to, lipid rafts where they find their substrate(s). This hypothesis is in agreement with the enhanced FceRI-associated SPHK activity seen in the raft compartment 5 min after IgE-Ag activation. While the overall increase in SPHK activity in the total raft fractions of CPII cells is slight to moderate, IPs of FceRI and normalization to the amount of precipitated $\gamma$-chain in BMMC showed that for the FceRI bound SPHK in the rafts, induction of its activity is essentially an all or none process (Fig. 7B). Given that the induction of total SPHK activity in lipid rafts is not an all or none process (Fig. 7A), we interpret this to mean that there is SPHK activity in lipid rafts under nonstimulated conditions that is not associated with FceRI (compare Fig. 7A to B). Whether the increase in FceRI-associated SPHK1 activity results from recruitment of resident SPHK1 or from the comigration with FceRI into the lipid raft domains, following IgE-Ag stimulation, is unclear. Conversely, the enhancement in the tyrosine kinase activity of Lyn seems to be subject to a similar twofold activation mechanism, by binding to SPHK and by binding to S, both of which synergize in this process. Stimulation of kinase activity by lipids is a well established phenomena, best exemplified by the activation of classical and novel PKCs by diacylglycerol but now known to extend to numerous tyrosine kinases. The findings suggest that although lipid raft-localized Lyn kinase may be active in resting cells (51), its activity may be enhanced by its interaction with SPHK and S. This may be an important finding in the context of prior studies demonstrating that the activ- ity of FceRI-associated Lyn kinase is unchanged prior to and after IgE-Ag stimulation $(35,50,51)$. As these experiments were in vitro kinase assays where SPHK or S were not added, or may not have been present in the IP material, the influence of the latter on Lyn activity would not have been noted. Our findings take into account that both Lyn and FceRI migrate into the sphingolipid-enriched raft domains and argue that the FceRI-associated SPHK1 activity in these domains is induced upon IgE-Ag stimulation. In this context, our finding that $\mathrm{S}$ promotes the activity of Lyn kinase is not surprising but fits well with the concept of the local concentration of $\mathrm{S}$ playing a role in inducing or sustaining the activity of the SPHK1/Lyn complex. On the contrary, S1P that is generated by the enhanced SPHK activity (that is directly bound to Lyn) provides a downregulatory signal for Lyn's tyrosine kinase activity. A negative regulatory (lipid) feedback loop controlling Lyn tyrosine kinase activity is also logical, since it was recently found that Lyn exerts a negative regulatory role in mast cell activation (28), and the dissociation of Lyn from FceRI (possibly as a mechanism to avoid negative regulation), after receptor chain phosphorylation, has been described previously (32). While all our data are in agreement with an initial stimulatory and subsequent inhibitory role for S and S1P, respectively, on Lyn activity, several puzzles remain; i.e., where does the first interaction between Lyn and SPHK take place (in the rafts or outside)? Is SPHK1 able to phosphorylate S when it is bound to Lyn? Does exogenous addition of S1P behave identically to S1P generated from Lyn bound S? These are experimentally difficult questions, given the fact that addressing them requires the complete separation (without contamination) of the free from protein-bound S and S1P.

The functional role of SPHK1 activity remains an enigma. While its product (S1P) has been associated with $\mathrm{Ca}^{2+}$ mobilization, evidence to the contrary also exists, since inhibitors of PLC $\gamma$ effectively inhibit mast cell and basophil $\mathrm{Ca}^{2+}$ responses and degranulation $(44,45)$. It should be noted that we also found no evidence for an association of SPHK1 activity with $\mathrm{Ca}^{2+}$ mobilization, since reintroduction of Lyn kinase into $\mathrm{Lyn}^{-1-}$ mast cells, which restored SPHK1 activity, did not restore the calcium response in these cells (data not shown). This finding was unexpected. However, we cannot exclude incorrect targeting of ectopic Lyn or a developmental defect of Lyn deficiency that is not restored by retroviral expression of Lyn.

Regardless, what is clear from our findings is that SPHK1 and Lyn kinase form an early partnership in IgE-dependent mast cell activation. Previous work (37) established the decisive nature of the balance of S:S1P in FceRI-dependent mast cell activation. The present work provides a possible mechanism through the effects of S and S1P on Lyn kinase activity. Additionally, we find that SPHK1 activity is finely regulated by its interaction with Lyn kinase. These findings, together with the observed requirement of SPHK1/Lyn interaction for FceRI association, clearly place SPHK1 proximal to the receptor as a regulator of early events. This may be a key function, analogous to the role of another lipid kinase (PI3K), in regulating the activity of tyrosine kinases, lipases, and adaptor proteins among a host of other proteins (6). 


\section{ACKNOWLEDGMENTS}

We are grateful to all our colleagues at the Novartis Research Institute Vienna who have supported this work.

The work of J.R. is supported by the National Institute of Arthritis and Musculoskeletal and Skin Diseases, National Institutes of Health, Department of Health and Human Services.

\section{REFERENCES}

1. Albrecht, B., M. Woisetschlager, and M. W. Robertson. 2000. Export of the high affinity IgE receptor from the endoplasmic reticulum depends on a glycosylation-mediated quality control mechanism. J. Immunol. 165:56865694 .

2. Baumruker, T., G. G. Pendl, and E. E. Prieschl. 1997. Gene regulation after Fc epsilon RI stimulation in the murine mast cell line CPII. Int. Arch. Allergy Immunol. 113:39-41.

3. Baumruker, T., and E. E. Prieschl. 2002. Sphingolipids and the regulation of the immune response. Semin. Immunol. 14:57-63.

4. Billich, A., F. Bornancin, P. Devay, D. Mechtcheriakova, N. Urtz, and T. Baumruker. 2003. Phosphorylation of the immunomodulatory drug FTY720 by sphingosine kinases. J. Biol. Chem. 278:47408-47415.

5. Brinkmann, V., M. D. Davis, C. E. Heise, R. Albert, S. Cottens, R. Hof, C Bruns, E. Prieschl, T. Baumruker, P. Hiestand, C. A. Foster, M. Zollinger, and K. R. Lynch. 2002. The immune modulator FTY720 targets sphingosine 1-phosphate receptors. J. Biol. Chem. 277:21453-21457.

6. Cantley, L. C. 2002. The phosphoinositide 3-kinase pathway. Science 296: $1655-1657$

7. Choi, O. H., J. H. Kim, and J. P. Kinet. 1996. Calcium mobilization via sphingosine kinase in signalling by the $\mathrm{Fc}$ epsilon RI antigen receptor. Nature 380:634-636.

8. Davis, R. J., N. Girones, and M. Faucher. 1988. Two alternative mechanisms control the interconversion of functional states of the epidermal growth factor receptor. J. Biol. Chem. 263:5373-5379.

9. Edsall, L. C., G. G. Pirianov, and S. Spiegel. 1997. Involvement of sphingosine-1-phosphate in nerve growth factor-mediated neuronal survival and differentiation. J. Neurosci. 17:6952-6960.

10. Eiseman, E., and J. B. Bolen. 1992. Engagement of the high-affinity $\operatorname{IgE}$ receptor activates src protein-related tyrosine kinases. Nature 355:78-80.

11. Field, K. A., D. Holowka, and B. Baird. 1995. FckRI-mediated recruitment of p53/p56lyn to detergent-resistant membrane domains accompanies cellular signaling. Proc. Natl. Acad. Sci. USA 92:9201-9205.

12. Field, K. A., D. Holowka, and B. Baird. 1997. Compartmentalized activation of the high affinity immunoglobulin $\mathrm{E}$ receptor with membrane domains. J. Biol. Chem. 272:4276-4280.

13. Hayashi, S., T. Okada, N. Igarashi, T. Fujita, S. Jahangeer, and S. Nakamura. 2002. Identification and characterization of RPK118, a novel sphingosine kinase-1-binding protein. J. Biol. Chem. 277:33319-33324.

14. Hinkovska-Galcheva, V. T., L. A. Boxer, P. J. Mansfield, D. Harsh, A. Blackwood, and J. A. Shayman. 1998. The formation of ceramide-1-phosphate during neutrophil phagocytosis and its role in liposome fusion. J. Biol. Chem. 273:33203-33209.

15. Johnson, K. R., K. P. Becker, M. M. Facchinetti, Y. A. Hannun, and L. M. Obeid. 2002. PKC-dependent activation of sphingosine kinase 1 and translocation to the plasma membrane. Extracellular release of sphingosine-1phosphate induced by phorbol 12-myristate 13-acetate (PMA). J. Biol. Chem. 277:35257-35262.

16. Jolly, P. S., M. Bektas, A. Olivera, C. Gonzalez-Espinosa, R. L. Proia, J. Rivera, S. Milstien, and S. Spiegel. 2004. Transactivation of sphingosine-1phosphate receptors by FceRI triggering is required for normal mast cell degranulation and chemotaxis. J. Exp. Med. 199:959-970.

17. Kawakami, Y., J. Kitaura, A. B. Satterthwaite, R. M. Kato, K. Asai, S. E Hartman, M. Maeda-Yamamoto, C. A. Lowell, D. J. Rawlings, O. N. Witte, and T. Kawakami. 2000. Redundant and opposing functions of two tyrosine kinases, Btk and Lyn, in mast cell activation. J. Immunol. 165:1210-1219.

18. King, C. C., F. T. Zenke, P. E. Dawson, E. M. Dutil, A. C. Newton, B. A. Hemmings, and G. M. Bokoch. 2000. Sphingosine is a novel activator of 3-phosphoinositide-dependent kinase 1. J. Biol. Chem. 275:18108-18113.

19. Lacana, E., M. Maceyka, S. Milstien, and S. Spiegel. 2002. Cloning and characterization of a protein kinase A anchoring protein (AKAP)-related protein that interacts with and regulates sphingosine kinase 1 activity. J. Biol. Chem. 277:32947-32953.

20. Liu, H., M. Sugiura, V. E. Nava, L. C. Edsall, K. Kono, S. Poulton, S Milstien, T. Kohama, and S. Spiegel. 2000. Molecular cloning and functional characterization of a novel mammalian sphingosine kinase type 2 isoform. J. Biol. Chem. 275:19513-19520.

21. Mazurek, N., T. Megidish, S. Hakomori, and Y. Igarashi. 1994. Regulatory effect of phorbol esters on sphingosine kinase in BALB/C 3T3 fibroblasts (variant A31): demonstration of cell type-specific response-a preliminary note. Biochem. Biophys. Res. Commun. 198:1-9.

22. McDonald, O. B., Y. A. Hannun, C. H. Reynolds, and N. Sahyoun. 1991 Activation of casein kinase II by sphingosine. J. Biol. Chem. 266:21773-21776.
23. Megidish, T., T. White, K. Takio, K. Titani, Y. Igarashi, and S. Hakomori. 1995. The signal modulator protein 14-3-3 is a target of sphingosine- or $\mathrm{N}, \mathrm{N}$-dimethylsphingosine-dependent kinase in 3T3(A31) cells. Biochem. Biophys. Res. Commun. 216:739-747.

24. Melendez, A., R. A. Floto, D. J. Gillooly, M. M. Harnett, and J. M. Allen. 1998. Fc gamma RI coupling to phospholipase D initiates sphingosine kinase-mediated calcium mobilization and vesicular trafficking. J. Biol. Chem. 273:9393-9402.

25. Melendez, A. J., and A. K. Khaw. 2002. Dichotomy of Ca2 + signals triggered by different phospholipid pathways in antigen stimulation of human mast cells. J. Biol. Chem. 277:17255-17262.

26. Meyer zu Heringdorf, D., H. Lass, R. Alemany, K. T. Laser, E. Neumann, C. Zhang, M. Schmidt, U. Rauen, K. H. Jakobs, and C. J. van Koppen. 1998. Sphingosine kinase-mediated $\mathrm{Ca} 2+$ signalling by G-protein-coupled receptors. EMBO J. 17:2830-2837.

27. Nishizumi, H., and T. Yamamoto. 1997. Impaired tyrosine phosphorylation and $\mathrm{Ca} 2+$ mobilization, but not degranulation, in lyn-deficient bone mar row-derived mast cells. J. Immunol. 158:2350-2355.

28. Odom, S., G. Gomez, M. Kovarova, Y. Furumoto, J. J. Ryan, H. V. Wright, C. Gonzales-Espinosa, M. L. Hibbs, K. W. Harder, and J. Rivera. 2004 Negative regulation of immunoglobulin E-dependent allergic responses by Lyn kinase. J. Exp. Med. 199:1491-1502.

29. Olivera, A., T. Kohama, L. Edsall, V. Nava, O. Cuvillier, S. Poulton, and S. Spiegel. 1999. Sphingosine kinase expression increases intracellular sphingosine-1-phosphate and promotes cell growth and survival. J. Cell Biol. 147:545-558.

30. Olivera, A., T. Kohama, Z. Tu, S. Milstien, and S. Spiegel. 1998. Purification and characterization of rat kidney sphingosine kinase. J. Biol. Chem. 273: $12576-12583$.

31. Olivera, A., and S. Spiegel. 1993. Sphingosine-1-phosphate as second messenger in cell proliferation induced by PDGF and FCS mitogens. Nature 365:557-560.

32. Ortega, E., M. Lara, I. Lee, C. Santana, A. M. Martinez, J. R. Pfeiffer, R. J. Lee, B. S. Wilson, and J. M. Oliver. 1999. Lyn dissociation from phosphorylated Fc epsilon RI subunits: a new regulatory step in the Fc epsilon R signaling cascade revealed by studies of Fc epsilon RI dimer signaling activity. J. Immunol. 162:176-185.

33. Parravicini, V., M. Gadina, M. Kovarova, S. Odom, C. Gonzalez-Espinosa, Y. Furumoto, S. Saitoh, L. E. Samelson, J. J. O'Shea, and J. Rivera. 2002 Fyn kinase initiates complementary signals required for IgE-dependent mast cell degranulation. Nat. Immunol. 3:741-748.

34. Pitson, S. M., R. J. D'Andrea, L. Vandeleur, P. A. Moretti, P. Xia, J. R. Gamble, M. A. Vadas, and B. W. Wattenberg. 2000. Human sphingosine kinase: purification, molecular cloning and characterization of the native and recombinant enzymes. Biochem. J. 350:429-441.

35. Pribluda, V. S., C. Pribluda, and H. Metzger. 1994. Transphosphorylation as the mechanism by which the high-affinity receptor for IgE is phosphorylated upon aggregation. Proc. Natl. Acad. Sci. USA 91:11246-11250.

36. Prieschl, E. E., and T. Baumruker. 2000. Sphingolipids: second messengers, mediators and raft constituents in signaling. Immunol. Today 21:555-560.

37. Prieschl, E. E., R. Csonga, V. Novotny, G. E. Kikuchi, and T. Baumruker. 1999. The balance between sphingosine and sphingosine-1-phosphate is decisive for mast cell activation after Fc epsilon receptor I triggering. J. Exp Med. 190:1-8

38. Prieschl, E. E., R. Csonga, V. Novotny, G. E. Kikuchi, and T. Baumruker. 2000. Glycosphingolipid-induced relocation of Lyn and Syk into detergentresistant membranes results in mast cell activation. J. Immunol. 164:53895397.

39. Prieschl, E. E., G. G. Pendl, N. E. Harrer, and T. Baumruker. 1995. p21ras links Fc epsilon RI to NF-AT family member in mast cells. The AP3-like factor in this cell type is an NF-AT family member. J. Immunol. 155:49634970.

40. Saitoh, S., R. Arudchandran, T. S. Manetz, W. Zhang, C. L. Sommers, P. E Love, J. Rivera, and L. E. Samelson. 2000. LAT is essential for Fc(epsilon)RI-mediated mast cell activation. Immunity 12:525-535.

41. Saitoh, S., S. Odom, G. Gomez, C. L. Sommers, H. A. Young, J. Rivera, and L. E. Samelson. 2003. The four distal tyrosines are required for LATdependent signaling in FcepsilonRI-mediated mast cell activation. J. Exp. Med. 198:831-843.

42. Spiegel, S., O. Cuvillier, L. C. Edsall, T. Kohama, R. Menzeleev, Z. Olah, A. Olivera, G. Pirianov, D. M. Thomas, Z. Tu, J. R. Van Brocklyn, and F. Wang. 1998. Sphingosine-1-phosphate in cell growth and cell death. Ann. N. Y. Acad. Sci. 845:11-18.

43. Suchard, S. J., V. Hinkovska-Galcheva, P. J. Mansfield, L. A. Boxer, and J. A. Shayman. 1997. Ceramide inhibits IgG-dependent phagocytosis in human polymorphonuclear leukocytes. Blood 89:2139-2147.

44. Tedeschi, A., M. Lorini, S. Gibelli, and A. Miadonna. 2000. Effects of protein kinase $\mathrm{C}$ and phospholipase $\mathrm{C}$ inhibitors on IgE-dependent and IgE-independent basophil histamine release. Inflamm. Res. 49:480-485.

45. Trieselmann, N. Z., J. Soboloff, and S. A. Berger. 2003. Mast cells stimulated by membrane-bound, but not soluble, steel factor are dependent on phospholipase C activation. Cell. Mol. Life Sci. 60:759-766. 
46. Wang, F., J. R. Van Brocklyn, J. P. Hobson, S. Movafagh, Z. ZukowskaGrojec, S. Milstien, and S. Spiegel. 1999. Sphingosine 1-phosphate stimulates cell migration through a G(i)-coupled cell surface receptor. Potential involvement in angiogenesis. J. Biol. Chem. 274:35343-35350.

47. Xia, P., J. R. Gamble, K. A. Rye, L. Wang, C. S. Hii, P. Cockerill, Y Khew-Goodall, A. G. Bert, P. J. Barter, and M. A. Vadas. 1998. Tumor necrosis factor-alpha induces adhesion molecule expression through the sphingosine kinase pathway. Proc. Natl. Acad. Sci. USA 95:14196-14201.

48. Xia, P., L. Wang, J. R. Gamble, and M. A. Vadas. 1999. Activation of sphingosine kinase by tumor necrosis factor-alpha inhibits apoptosis in human endothelial cells. J. Biol. Chem. 274:34499-34505.
49. Xia, P., L. Wang, P. A. Moretti, N. Albanese, F. Chai, S. M. Pitson, R. J. D'Andrea, J. R. Gamble, and M. A. Vadas. 2002. Sphingosine kinase interacts with TRAF2 and dissects tumor necrosis factor-alpha signaling. J. Biol. Chem. 277:7996-8003

50. Yamashita, T., S. Y. Mao, and H. Metzger. 1994. Aggregation of the highaffinity IgE receptor and enhanced activity of p53/56lyn protein-tyrosine kinase. Proc. Natl. Acad. Sci. USA 91:11251-11255.

51. Young, R. M., D. Holowka, and B. Baird. 2003. A lipid raft environmen enhances Lyn kinase activity by protecting the active site tyrosine from dephosphorylation. J. Biol. Chem. 278:20746-20752. 